\title{
Nepheline crystallization in boron-rich alumino-silicate glasses as investigated by multi-nuclear NMR, Raman, \& Mössbauer spectroscopies
}

\author{
John McCloy, ${ }^{1 *}$ Nancy Washton, ${ }^{2}$ Paul Gassman, ${ }^{3}$ Jose Marcial, ${ }^{1}$ Jamie Weaver, ${ }^{1}$ Ravi Kukkadapu ${ }^{2}$ \\ ${ }^{1}$ Washington State University, Pullman, WA 99164, USA \\ ${ }^{2}$ Environmental Molecular Sciences Laboratory, Pacific Northwest National Laboratory, Richland, WA \\ 99352, USA \\ ${ }^{3}$ Pacific Northwest National Laboratory, Richland, WA 99352, USA
}

*Corresponding author: Ph: 509-335-7796; Fax: 509-335-4662; email: john.mccloy@wsu.edu

\begin{abstract}
A spectroscopic study was conducted on six simulant nuclear waste glasses using multi-nuclear NMR, Raman, and Mössbauer spectroscopies exploring the role of $\mathrm{Si}, \mathrm{Al}, \mathrm{B}, \mathrm{Na}$, and $\mathrm{Fe}$ in the glass network with the goal of understanding melt structure precursors to deleterious nepheline crystal formation. NMR showed two sites each for $\mathrm{Al}, \mathrm{Si}$, and $\mathrm{Na}$ in the samples which crystallized significant amounts of nepheline, and B speciation changed, typically resulting in more B(IV) after crystallization. Raman spectroscopy suggested some of the glass structure is composed of metaborate chains or rings, thus significant numbers of non-bridging oxygen and a separation of the borate from the aluminosilicate network. Mössbauer, combined with Fe redox chemical measurements, showed Fe playing a minor role in these glasses, mostly as $\mathrm{Fe}^{3+}$, but iron oxide spinel forms with nepheline in all cases. A model of the glass network and allocation of non-bridging oxygens (NBOs) was computed using experimental $\mathrm{B}(\mathrm{IV})$ fractions which predicted a large amount of NBO consistent with Raman spectra of metaborate features.
\end{abstract}

Keywords: nuclear waste glass; alumino-boro-silicate; NMR; Mossbauer; nepheline 


\section{Introduction}

\subsection{Nuclear waste glasses}

Currently the largest US nuclear waste repository is the Hanford site located in southeastern Washington. This site contains 177 subterranean waste tanks each with a capacity greater than 50,000 gallons [1]. The result of early plutonium production, more than half of this waste has been identified to possess high concentrations of $\mathrm{Na}$ - and Al-containing compounds. Approximately 90 mass\% of the waste is a liquid supernatant with low levels of radiation referred to as low-activity waste (LAW) [2]. Heavy precipitates and $>95 \%$ of the radioactive material settles in the waste tanks as high-level waste (HLW) [2]. This work pertains to HLW vitrification, in particular, the formation of crystalline phases during cooling after the vitrification process which can have a deleterious effect on the chemical durability of glass.

Crystallization in HLW glasses proceeds much slower than in polycrystalline systems [3]. After feed-to-glass conversion the vitrified waste will be poured into stainless steel canisters and allowed to cool in ambient air [3]. The cooling profile of the canister will allow for rapid cooling of the outer melt but will result in slow cooling of melt in the canister center. As dictated by kinetics, monitoring the crystallization of HLW simulant glass samples that are poured on a stainless steel plate and air quenched (Q) provide a lower-bound crystallization behavior since the samples will experience rapid cooling [3]. To replicate the slowest cooled portions, a standard cooling profile known as canister centerline cooling (CCC) is typically performed, with the specific cooling profile determined by the expected operation. By performing CCC heat treatments, the goal is to replicate the upper-bound crystallization behavior of a HLW glass [3]. Recently, simulations have been made of canister thermal profiles considering different pour schemes [3], and different cooling curves have been examined to study crystallization in crucible studies [4].

In nuclear waste vitrification, nuclear waste is mixed with glass-forming additives (e.g., $\mathrm{SiO}_{2}$ and $\mathrm{H}_{3} \mathrm{BO}_{3}$ ) then charged into a furnace and melted into a glass. Glass compositions are developed to maximize the waste loading, corrosion resistance, and the rate of melting while minimizing the melting temperature and the crystallization of secondary phases [5-7]. The crystallization of nepheline $\left(\mathrm{NaAlSiO}_{4}\right)$ and similar sodium aluminosilicates decreases the corrosion resistance of high-waste-loaded glasses by extracting the glass forming components $\mathrm{Al}_{2} \mathrm{O}_{3}$ and $\mathrm{SiO}_{2}[8]$.

It has been demonstrated over the years that nepheline is unlikely to form outside of its primary phase field in the ternary $\mathrm{Na}_{2} \mathrm{O}-\mathrm{Al}_{2} \mathrm{O}_{3}-\mathrm{SiO}_{2}$ submixture phase diagram, and the "nepheline discriminator" (ND) was introduced to describe this constraint limiting compositions to silica-rich regions [9]. One recent attempt that extended the range of compositions allowable for formulation while still avoiding nepheline formation appealed to a combined set of criteria including ND along with optical basicity (OB) [10]. It is generally accepted that particular oxides, notably $\mathrm{CaO}$ and $\mathrm{B}_{2} \mathrm{O}_{3}$, have a profound effect on the propensity for nepheline formation [11], but it is as yet unknown how these oxides change the glass structure making HLW glass more or less susceptible to nepheline formation. The ND-OB model has had mixed success, as there are still some glasses which it fails to predict as forming nepheline. To improve upon it or guide the development of improved models, a more fundamental understanding of the changes in melt structure upon cooling are needed.

\subsection{Structure of alkali alumino-boro-silicate glasses containing iron}

Many studies have investigated the local coordination of $\mathrm{Al}, \mathrm{B}, \mathrm{Si}$, and $\mathrm{O}$ in alkali-alumino-borosilicate glasses using Raman spectroscopy [9] and nuclear magnetic resonance (NMR) [12, 13], and some work has been done looking at additional physical properties [14] crystallization behavior [15], and thermodynamics [16-18], yet no definitive understanding is available. In a few cases, models have been proposed to predict speciation of local atomic arrangements. One such qualitative model is based on 
local charge balance on the oxygens of alkaline-earth boro-aluminate crystals, where results from ${ }^{11} \mathrm{~B}$ and ${ }^{27} \mathrm{Al}$ magic angle spinning (MAS)-NMR stressed the importance of three-coordinated oxygen $\mathrm{O}(\mathrm{III})$, where parentheses here and elsewhere denote nearest neighbor coordination, and indicated the importance of $\mathrm{Al}(\mathrm{V})$ and $\mathrm{Al}(\mathrm{VI})$ in all composition ranges [19]. In another example, Du and Stebbins [12] presented a modified Dell and Bray-type model [20] to include aluminum (i.e., alkali-alumino-borosilicate) and to describe boron speciation. Various tetrahedra compete for sodium, the modifier generally preferring $\mathrm{Al}$, then $\mathrm{B}$, then $\mathrm{Si}$ [21]. Tetrahedra building, on the other hand, is believed to start with Si then proceed to Al(IV), Fe(IV), and B(IV) (if present), as long as charged tetrahedron nearneighbor avoidance is maintained [12, 22].

Both boron and aluminum coordination are affected by modifier-cation field strength. In aluminoboro-silicates containing both $\mathrm{Na}$ and $\mathrm{Ca}$, increasing the amount of $\mathrm{Ca}$ increases $\mathrm{Al}(\mathrm{V})$ [13], but has been said to increase $B(I V)$ [23] or decrease it [13]. It has been shown in aluminoborates that higher-fieldstrength cations (e.g., Mg), can shift the normally encountered "chemical ordering" (i.e., Al and B tetrahedra avoidance due to Coulomb repulsion) seen in $\mathrm{Na}$ and $\mathrm{Ca}$ aluminoborates to the "statistical random mixing" of tetrahedra seen in Mg alumino-borate [24], and to an extent in Ca alumino-borosilicates [13]. Higher coordinated alumina units, $\mathrm{Al}(\mathrm{V})$ and $\mathrm{Al}(\mathrm{IV})$, can be charge compensated by $2^{+}$ cations ( $\mathrm{Ca}, \mathrm{Mg}$ ) or $3^{+}$cations ( $\left.\mathrm{B}, \mathrm{Al}, \mathrm{La}\right)$, and at the same time tend to "stabilize" $\mathrm{B}(\mathrm{IV})$ tetrahedra, acting as weakly positive ions themselves $[19,24,25]$.

Effects of differing $\mathrm{Al} / \mathrm{B}$ ratios are explained by the local charge balance model [19], as $\mathrm{B}(\mathrm{III})$ is needed to stabilize units containing the charged $\mathrm{Al}(\mathrm{IV})$, so as more $\mathrm{Al}$ is added, the fraction of $\mathrm{B}$ (III) increases relative to $B(I V)$ [23]. It has also been shown by MAS-NMR in alumino-boro-silicates that the presence of $\mathrm{Al}$ decreased the expected conversion of $\mathrm{B}(\mathrm{III})$ to $\mathrm{B}(\mathrm{IV})$, since Na reacts preferentially with $\mathrm{Al}$ as a charge compensator, so only the Na remaining after associating with Al may associate to make $B(I V)$ $[21,26]$. The position of $B(I I I)$ in the glass structure is known to also vary, and NMR data has shown that the ratio of ring $\mathrm{B}(\mathrm{III})$ to non-ring $\mathrm{B}(\mathrm{III})$ increases with increasing $\mathrm{B} / \mathrm{Al}$ and leaching tests have indicated that ring $\mathrm{B}(\mathrm{III})$ is undesirable for chemical durability [26]. Therefore despite the desirable effect seen at high $\mathrm{B}_{2} \mathrm{O}_{3}$ concentrations for suppressing nepheline formation in nuclear waste glasses [8], excessively high $\mathrm{B}_{2} \mathrm{O}_{3}$ is likely to result in undesirable ring $\mathrm{B}(\mathrm{III})$ structures.

The effects of Fe on silicate glass structure are less well-understood than Al and B, particularly when the other tetrahedra are present. NMR studies are not generally useful when Fe concentrations are much above $5 \mathrm{wt} \% \mathrm{Fe}_{2} \mathrm{O}_{3}$, so Raman and infrared spectroscopy, boron K-edge $\mathrm{x}$-ray absorption (XANES and EXAFS) and Mössbauer spectroscopy have been used to study glasses with high Fe concentrations [27]. $\mathrm{Fe}^{3+}$ is generally assumed to be a glass-former in tetrahedral configuration, $\mathrm{Fe}$ (IV) similar to $\mathrm{Al}(\mathrm{IV})$, while $\mathrm{Fe}^{2+}$ is a network modifier. However, redox and coordination behavior of $\mathrm{Fe}$ in silicate glass is complicated, and the effect of alkali and alkaline earths can be either "collective" (all modifiers acting similarly) or "selective" (where modifiers compete with one another) [28, 29]. Simple alkali and alkaline earth iron silicates have been well-studied due to their importance in silicate geochemistry, especially orthosilicates $\left(Q^{0}\right)$ such as olivine (e.g., fayalite) and chain silicates $\left(Q^{2}\right)$ such as pyroxene (e.g., hedenbergite, augite). Low concentrations of $\mathrm{Fe}(<10 \mathrm{~mol} \%$ as $\mathrm{FeO})$ are generally thought to have little effect on boron speciation in alkali borosilicate glasses which do not contain aluminum [27]. Similar to the effect of $\mathrm{Al}_{2} \mathrm{O}_{3}$, additions of $\mathrm{Fe}_{2} \mathrm{O}_{3}$ to alkali borosilicates causes repolymerization since $\mathrm{Fe}^{3+}$ requires charge compensation in tetrahedral coordination [30]. At very low Fe contents $\left(<1\right.$ mol\% $\left.\mathrm{Fe}_{2} \mathrm{O}_{3}\right)$ in sodium silicate glass, $\mathrm{Fe}$ is present as $\mathrm{Fe}^{3+}$ in both octahedral and tetrahedral environments and $\mathrm{Fe}^{2+}$ in octahedral coordination, with the distribution depending on the extent of reducing conditions [31]. In nuclear waste glasses, Fe generally precipitates from the glass in spinels [32-34], but high silica compositions and specific heat-treatment temperatures or cooling profiles 
can cause precipitation of other iron bearing minerals $[33,35]$. Recently, high Fe silicate glasses ( 20 wt\% $\mathrm{Fe}_{2} \mathrm{O}_{3}$ ) containing low $\mathrm{Al}_{2} \mathrm{O}_{3}$ and $\mathrm{B}_{2} \mathrm{O}_{3}$ but high $\mathrm{Na}_{2} \mathrm{O}$ have shown poor chemical durability since there is an excess of $\mathrm{Na}_{2} \mathrm{O}$ which creates $\mathrm{Si}$ non-bridging oxygens (NBO). In this case there are not enough $\mathrm{T}^{3+}\left(\mathrm{Fe}^{3+}, \mathrm{Al}^{3+}, \mathrm{B}^{3+}\right)$ tetrahedra requiring alkali compensation [36].

\subsection{Structure of nepheline: crystalline and non-crystalline analogues}

It is important to understand the crystal structure of nepheline in order to appreciate its crystallization in the complex melt. The nepheline structure is known as a "stuffed tridymite $\left(\mathrm{SiO}_{2}\right)$ derivative" [37] in that 6-membered ring layers are stacked and the channels in these rings are "stuffed" with various cations. The layer stacking along the c-axis is typically one of two types. If adjacent layers are mirror images of each other, the arrangement is known as eclipsed or cis, such as in nepheline or tridymite. If adjacent layers are rotated $180^{\circ}$ around each other and shifted laterally, the arrangement is known as staggered or trans, such as in kalsilite $\left(\mathrm{KAISiO}_{4}\right)$ and malinkoite $\left(\mathrm{NaBSiO}_{4}\right)$ [38].

There are four types of tetrahedral sites in the nepheline structure (hexagonal space group $\mathrm{P}_{3}$ ), indicated as $\mathrm{T}(1), \mathrm{T}(2), \mathrm{T}(3)$, and $\mathrm{T}(4)$ (see Figure 1). Al and Si tetrahedra form 6-membered rings which alternate "up" and "down", and in general the Al and Si alternate in an ordered way in the hexagonal nepheline polymorph. However, the nepheline crystal is quite flexible, and Si-rich nephelines have been noted [39], as well as common substitution with $\mathrm{Ca}$, Fe, and other cations [40]. In general, however, it is believed that the $T(1)$ site is aluminum ( $\mathrm{Al} \geq \mathrm{Si}$ ), the $\mathrm{T}(2)$ site is silicon ( $\mathrm{Si}>\mathrm{Al}$ ), the $\mathrm{T}(3)$ site is silicon ( $\mathrm{Si}>\mathrm{Al}$ ), and the $\mathrm{T}(4)$ site is aluminum $(\mathrm{Al}>\mathrm{Si})$, where the parenthesis indicates the relative likelihood of that network former on the tetrahedral site [40]. In the original description of nepheline, these sites were called $T_{G}$, which is a "general" tetrahedral site with two sodium channels and one hexagonal channel surrounding it (includes $\mathrm{T}(3)$ and $\mathrm{T}(4)$ ), and $\mathrm{T}_{\mathrm{S}}$, which is a "special" tetrahedral site with three sodium channels surrounding it (which is further distinguished in modern nomenclature as T(1) and T(2)) [41, 42]. It is generally asserted that the $T(1)$ and $T(2)$ sites are fully ordered, with $T(3)$ and $T(4)$ sites partially disordered in $\mathrm{Al}$ and $\mathrm{Si}$, but this observation may be due to antiphase boundaries which are destroyed when heated to high temperatures [43]. Short-range tetrahedral structure in nepheline is ordered according to previous NMR results [44]. Additionally, Fe is almost always present in natural nepheline crystals [45] and it is generally assumed to be in the $3+$ state in an aluminum site [40] as the $\mathrm{Fe}^{2+}$ ion is medium-sized and thought to be unsuited for occupation of the channel sites [46]. There is some evidence that $\mathrm{B}^{3+}$ can enter the nepheline structure in a tetrahedral site in synthetic materials, but exactly which one remains unclear [26].

The two types of channels of 6-membered rings in nepheline are denoted the A-site and the B-site [40]. Natural nepheline has nominal stoichiometry $\mathrm{KNa}_{3} \mathrm{Al}_{4} \mathrm{Si}_{4} \mathrm{O}_{16}$ [47], though oftentimes is it written with a doubled unit cell with 32 oxygens. The A-site is a hexagonal channel and is normally occupied by $\mathrm{K}$ or vacancies in mineral nepheline. The B-site is a distorted "oval" channel containing $2 \mathrm{Na}$ atoms or minor amounts of $\mathrm{Ca}$. Natural nephelines (with one $\mathrm{K}$ per every three $\mathrm{Na}$ atoms) normally have $1 / 3$ vacancies on A-site $[40,48]$. When $\mathrm{Si}>\mathrm{Al}$, additional vacancies go on the A-site to keep charge balance [49]. If $\mathrm{Na}$ is substituted by $\mathrm{Ca}$, further vacancies may go on the A-site [48]. The real structure of nepheline minerals also involve coupling of K-vacancy ordering and oxygen-atom displacement in a complicated way, resulting in a modulated structure [40, 50-52]. Though this hexagonal nepheline structure is quite flexible and pure sodium nephelines can be $\mathrm{P}_{3}$ with $\mathrm{Na}$ atoms occupying off-center sites in the hexagonal channel [53], they also exhibit additional crystal structures such as $\mathrm{P} 6_{1}$ (hexagonal "trinepheline" [54]) and P112 (monoclinic "trinepheline" [55]) when there are no hexagonal channels 
for large ions. Only very recently has any spectroscopic data been obtained for monoclinic nepheline [56].

Pure sodium nepheline glasses have been produced and reported by several authors [57-59]. Interestingly, pure albite $\left(\mathrm{NaAlSi}_{3} \mathrm{O}_{8}\right.$ or $\left.\mathrm{NaAlSiO}_{4}-2 \mathrm{SiO}_{2}\right)$ and jadeite $\left(\mathrm{NaAlSi}_{2} \mathrm{O}_{6}\right.$ or $\left.\mathrm{NaAlSiO}_{4}-\mathrm{SiO}_{2}\right)$ have also been produced, but their glass structure is significantly different than the respective crystalline structure $[59,60]$. Whereas albite is a feldspar with 4-membered rings of tetrahedral, and jadeite is a pyroxene (chain silicate) with 6-coordinated Al, quenched melts of these stoichiometries all form 6membered rings with both $\mathrm{Si}$ and $\mathrm{Al}$ in tetrahedral coordination. It was verified that the high temperature melt structure of albite glass was also 6-membered, and only with slow cooling did it crystallize and convert to 4-membered rings [61]. This observation strongly suggests that Na-Al-Si melts, even when Si-rich, consist of 6-membered rings of tetrahedra with $\mathrm{Na}$ filling the channels and causing variable distortion of the rings essentially like the nepheline topology.

Increased complexity is observed when glasses are made in the albite $\left(\mathrm{NaAlSi}_{3} \mathrm{O}_{8}\right)_{-}$ reedmergnerite $\left(\mathrm{NaBSi}_{3} \mathrm{O}_{8}\right)$ [62] or nepheline $\left(\mathrm{NaAlSiO}_{4}\right)$ - malinkoite $\left(\mathrm{NaBSiO}_{4}\right)$ [26] joins. Whereas crystalline reedmergnerite contains only $\mathrm{B}(\mathrm{IV})[20,63,64]$, glassy $\mathrm{NaBSi}_{3} \mathrm{O}_{8}$ contains $\sim 30 \% \mathrm{~B}(\mathrm{III})$ and glassy $\mathrm{NaB}_{0.2} \mathrm{Al}_{0.8} \mathrm{Si}_{3} \mathrm{O}_{8}$ contains $\sim 60 \% \mathrm{~B}(\mathrm{III})$, and $\mathrm{NMR}$ data suggest that the $\mathrm{B}(\mathrm{III})$ and $\mathrm{B}(\mathrm{IV})$ species do not mix but rather "cluster" in ways suggesting phase separation [62]. NMR data suggests an increase of $\mathrm{B}(\mathrm{IV})$ and disappearing non-ring $\mathrm{B}(\mathrm{III})$ along the join towards malinkoite with mixing between $\mathrm{Al}(\mathrm{IV})$ and $B(I I I)$. Raman data suggests the presence of $\mathrm{B}-\mathrm{Na}$ enriched and $\mathrm{Al}-\mathrm{Si}$ enriched clusters in glasses with the highest $\mathrm{B}$ tested, $\mathrm{NaAl}_{0.2} \mathrm{~B}_{0.8} \mathrm{SiO}_{4}$ [26]. Crystalline malinkoite is hexagonal and contains $\mathrm{B}(\mathrm{IV})$ and $\mathrm{Si}$ tetrahedra linked in 6-membered rings with two different "up"/"down" configurations and $\mathrm{Na}$ in the ditrigonal channels [65], but monoclinic forms of $\mathrm{NaBSiO}_{4}$ have also been produced with differing arrangement of "up"/" down" tetrahedra [38].

\subsection{Approach of this study}

The long-term goal of this study is to inform and guide nepheline formation models in nuclear waste glass formulations by comparing glass structural features between glasses that form nepheline and those that do not. We hope, then, to demonstrate correlations between quenched glass structure and tendency for nepheline formation, and correlate glass compositional space with structural moieties that favor (or disfavor) nepheline formation. Specifically, we anticipate that particular structural moieties including $\mathrm{Si}, \mathrm{Al}, \mathrm{B}$, and $\mathrm{Na}$ will directly correlate to propensity for nepheline formation.

This study has measured structure-related properties of glasses with compositions in similar positions on the ternary normalized $\mathrm{Na}_{2} \mathrm{O}-\mathrm{Al}_{2} \mathrm{O}_{3}-\mathrm{SiO}_{2}$ submixture phase diagram. These glasses failed the current ND-OB model in that they precipitate nepheline when they are not predicted to do so. In particular, the focus is on glasses with $>10 \mathrm{wt} \% \mathrm{~B}_{2} \mathrm{O}_{3}$ which still precipitate nepheline, and these tend to be located in the carnegieite phase field region near the stoichiometric sodium nepheline (or carnegieite) composition of $\mathrm{NaAlSiO}_{4}$ [10]. Quenched (Q) and canister centerline cooled (CCC) (slow cooled) glasses are then subjected to MAS-NMR and Raman spectroscopy to understand the structure of the glasses as a surrogate of the melt structure. Raman spectroscopy was used to measure the vibrational spectra, and MAS-NMR was used to measure the coordination environments of $\mathrm{Al}, \mathrm{Si}, \mathrm{Na}$, and B. Iron oxidation/reduction (redox) values were also collected and Mössbauer spectroscopy performed on a subset of the glasses to investigate the role of Fe in the glass. 


\section{Experimental methods}

\subsection{Selection of glasses for study}

Samples of high alumina glasses were obtained from previous studies and their compositions are listed in Table I. Glasses were selected from the database of nepheline-study glasses (523 glasses) [10] which was updated with 106 new entries. The $\mathrm{Na}_{2} \mathrm{O}-\mathrm{Al}_{2} \mathrm{O}_{3}-\mathrm{SiO}_{2}$ submixture ternary showing all 629 glasses is shown in the inset of Figure 2, while the glasses shown in Table I are overlain on a phase diagram in Figure 2. Glasses were originally formulated by Vitreous State Laboratory (VSL) (HLW-E-ANa-\# [66]) and Pacific Northwest National Laboratory (PNNL) (IWL-HAC-\# [67] and HLW-E-ANa-X(Y) [68]) but were re-made at PNNL for this study. Note that for ease of use in the text, abbreviations for glass names are used as indicated in Table II.

Glasses were initially selected based on the deliberate desire to investigate the effect of glass structure on nepheline formation for glasses with similar discriminators (ND, $O B$, and position on the $\mathrm{Na}_{2} \mathrm{O}-\mathrm{Al}_{2} \mathrm{O}_{3}-\mathrm{SiO}_{2}$ submixture ternary) but different crystallization behaviors. Additionally, the structure of the same glasses either quenched or slow cooled (CCC) were compared to see what changed in the glass structure when nepheline did or did not precipitate after heat treatment. Pairs of glasses were selected where ternary position and/or $\mathrm{OB}$ were similar and nepheline did or did not precipitate. Five compositional clusters of glasses were identified for investigation. A detailed spectroscopic investigation was conducted on a further subset of these. One subset of these glasses, all from the carnegieite primary phase field of the $\mathrm{Na}_{2} \mathrm{O}-\mathrm{Al}_{2} \mathrm{O}_{3}-\mathrm{SiO}_{2}$ submixture ternary, a particularly troublesome region, is described in this article. Rationale for the sub-selection of the glasses described here is as follows (note that full glass name is listed, followed by abbreviation in brackets which is used in the rest of the text, see Table II).

- Position in ternary ( $20 \mathrm{Na}_{2} \mathrm{O}-35 \mathrm{Al}_{2} \mathrm{O}_{3}-45 \mathrm{SiO}_{2}$ in wt\%): HLW-E-ANa-24 [24], HLW-E-ANa-25 [25], HLW-E-ANa-26 [26]. The main interest in these glasses was that they are all very similar compositions but one (24) forms no nepheline while the other two form large amounts of nepheline; HLW-E-ANa-13(3AI-3Si) [13] is significantly basic and forms a large fraction of nepheline by CCC treatment.

- Position in ternary ( $18 \mathrm{Na}_{2} \mathrm{O}-30 \mathrm{Al}_{2} \mathrm{O}_{3}-52 \mathrm{SiO}_{2}$ in wt\%): HLW-E-ANa-04 [4]; this glass formed nepheline like most in the previous group but had different levels of $\mathrm{Na} / \mathrm{Si} / \mathrm{Al}$.

- Position in ternary ( $30 \mathrm{Na}_{2} \mathrm{O}-37 \mathrm{Al}_{2} \mathrm{O}_{3}-33 \mathrm{SiO}_{2}$ in wt\%): IWL-HAC5-1 [5-1] has an extreme composition compared to normal borosilicate waste glasses with very low $\mathrm{Si}$ and high $\mathrm{Al}$ but with substantial $\mathrm{Na}$.

Glasses were batched and melted using oxides and carbonates. After batching, each glass was mixed in an agate mill for $\sim 3$ minutes and then placed into a platinum crucible ( $\mathrm{Pt} / 10 \% \mathrm{Rh})$ and melted for 1 hour at 1150 to $1400^{\circ} \mathrm{C}$. The glass was then air-quenched by pouring the melt onto a stainless steel pour plate. Most of the glasses showed undissolved solids (UDS) after cooling, so to increase homogeneity, glass from the first melt was ground to a powder in a tungsten carbide mill ( $\sim$ minutes) and melted a second time at the same or slightly lower temperature than the first melt. All the glasses were subsequently air-quenched again and resulting glasses had a uniform appearance after cooling, with no observed UDS. The glasses were heat-treated following the standard CCC procedure for the Hanford Waste Treatment \& Immobilization Plant [69]. All glasses after heat treatment appeared black in bulk and greenish-brown after crushing to powder. Detailed microscopy was not performed. X-ray diffraction (XRD) analyses were performed using a diffractometer with $\mathrm{Cu} \mathrm{K}_{\alpha}$ radiation (Bruker D8, Bruker AXS Inc., Madison, Wisconsin, USA) and data collected from 5 to $70^{\circ} 2 \theta$, in $0.015^{\circ}$ increments with a $0.3 \mathrm{~s}$ dwell. Backgrounds were subtracted and phases identified using JADE $6^{\odot}$ (Materials Data, 
Inc., Livermore, CA), and EVA (Bruker AXS DIFFRACplus) software. Semi-quantitative analysis was performed using TOPAS 4.2 software (Bruker AXS).

In addition to the aforementioned glasses, two "standards" were used to study the glass and crystal structure of nepheline. First, a powdered sample of stoichiometric sodium nepheline glass $\left(\mathrm{NaAlSiO}_{4}\right.$ ) was obtained from a previous study ( $x=1$ glass from [58]). Second, a specimen of nominally nepheline mineral (Ward's Scientific \# 46E5580) was used. The nepheline mineral was doped with 5 wt\% $\mathrm{CeO}_{2}$ standard powder (NIST 647b) for quantification. By XRD the sample was determined to contain the following minerals (by wt\%): nepheline (75.6\%), anorthite (5.3\%), albite low (3.1\%), sodalite (3.1\%), and amorphous (7.8\%). Other minor mineral phases such as kaliophilite and analcime may have been locally present in this rock.

\subsection{Raman spectroscopy}

Glasses were analyzed using a Horiba high-resolution confocal inverted-stage microscopic Raman spectrometer (Horiba LabRAM $800 \mathrm{HR}$ ) with 600 grooves/mm diffraction gratings, using a Nikon Eclipse Ti microscope. Laser excitation at $532 \mathrm{~nm}$ was provided by a Quantum Laser MPC-3000, which delivered $\sim 20 \mathrm{~mW}$ of power to samples with an approximate spot diameter of $1 \mu \mathrm{m}$ on the samples. Spectra were recorded using a Peltier-cooled Horiba Synapse CCD detector with a 1024 by 256 pixel array. The spectrometer was calibrated using the line positions of a mercury pen lamp, and the band position of an amorphous silicon wafer used for frequency verification. Spectral resolution of the system, as described, was $1.8 \mathrm{~cm}^{-1} /$ pixel with a laser spot size of $1.1 \mu \mathrm{m}$. The spectrometer was centered at $1000 \mathrm{~cm}^{-1}$ Raman shift from the $532 \mathrm{~nm}$ laser excitation allowing data collection from 1500 to 100 $\mathrm{cm}^{-1}$. The number of spectral acquisitions, count times, and the diameter of the confocal iris were varied to maximize the signal to noise ratio of spectra. Most glass spectra were acquired for 10 minutes for improved signal to noise ratios. For purposes of comparison, Raman spectra are normalized by laser power.

Raman analyses of these high-alumina glasses sought to identify crystalline phases precipitated in the glass to better understand the mechanisms of compositional segregation. Raman spectra from these glasses are composites of the crystalline phases and the intervening host glass.

\subsection{Nuclear Magnetic Resonance}

${ }^{23} \mathrm{Na}$ direct polarization (DP) experiments were conducted on a 20 Tesla wide bore Varian VNMRs spectrometer, utilizing a Varian $4.0 \mathrm{~mm}$ triple resonance probe operating in $\mathrm{HX}$ mode and tuned to a ${ }^{23} \mathrm{Na}$ frequency of $224.7678 \mathrm{MHz}$. Spectra were acquired by collecting 1024 transients using calibrated ${ }^{23} \mathrm{Na} \pi / 20$ pulses of $0.5 \mu \mathrm{s}$, a $325 \mathrm{kHz}$ sweep width, a spinning speed of $17 \mathrm{kHz}$, and a $2.0 \mathrm{~s}$ recycle delay. Time domain free induction decays were zero-filled once and apodized with exponential functions corresponding to $250 \mathrm{~Hz}$ of Lorentzian broadening prior to Fourier transformation. ${ }^{23} \mathrm{Na}$ resonances were referenced to $0.10 \mathrm{M} \mathrm{NaCl}(\mathrm{aq})$ at $0 \mathrm{ppm} .{ }^{23} \mathrm{Na}$ spin lattice relaxation $\left(\mathrm{T}_{1}\right)$ was measured utilizing a saturation recovery sequence with twelve logarithmic time points from 0.001-2.39 s. The $T_{1}$ analysis was conducted in Topspin with each resonance fitted using a single component.

${ }^{27} \mathrm{Al}$ DP experiments were conducted on a 14.1 Tesla narrow bore Varian VNMRs spectrometer, utilizing a $4.0 \mathrm{~mm}$ triple resonance probe operating in $\mathrm{HX}$ mode tuned to an ${ }^{27} \mathrm{Al}$ frequency of 156.3049 $\mathrm{MHz}$. Spectra were acquired by collecting 2048 transients using calibrated ${ }^{27} \mathrm{Al} \pi / 20$ pulses of $0.5 \mu \mathrm{s}$, a $416 \mathrm{kHz}$ sweep width, a spinning speed of $17 \mathrm{kHz}$, and a $2.0 \mathrm{~s}$ recycle delay. Time domain free induction 
decays were apodized with exponential functions corresponding to $200 \mathrm{~Hz}$ of Lorentzian broadening prior to Fourier transformation. ${ }^{27} \mathrm{Al}$ resonances were referenced to $0.1 \mathrm{M} \mathrm{AlCl}_{3}(\mathrm{aq})$ at $0 \mathrm{ppm}$.

${ }^{29} \mathrm{Si}$ DP experiments with ${ }^{1} \mathrm{H}$ decoupling were conducted on a 17.6 Tesla wide-bore Bruker Avance III spectrometer, utilizing a $4.0 \mathrm{~mm}$ double resonance $\mathrm{HX}$ probe tuned to resonance frequencies of 149.032 MHz for ${ }^{29} \mathrm{Si}$ and $750.219 \mathrm{MHz}$ for ${ }^{1} \mathrm{H}$. Spectra were acquired by collecting 2816-8192 transients using calibrated ${ }^{29} \mathrm{Si} \pi / 2$ pulses of $6.0 \mu \mathrm{s}, 35 \mathrm{kHz}{ }^{1} \mathrm{H}$ decoupling, a $100 \mathrm{kHz}$ sweep width, a spinning speed of $10 \mathrm{kHz}$, and a recycle delay of 2-90 s depending upon the longitudinal relaxation time, $\mathrm{T}_{1}$. Time domain free induction decays were apodized with exponential functions corresponding to $250 \mathrm{~Hz}$ of Lorentzian broadening prior to Fourier transformation. ${ }^{29} \mathrm{Si}$ resonances were referenced to tetramethylsilane (TMS) at $0 \mathrm{ppm}$ using tetrakis(trimethylsilyl)silane (TTMSS) as a secondary reference at $-9.8 \mathrm{ppm}$.

${ }^{11} \mathrm{~B}$ DP experiments were conducted on a 20 Tesla wide bore Varian VNMRs spectrometer, utilizing a $4.0 \mathrm{~mm}$ triple resonance probe operating in $\mathrm{HX}$ mode tuned to a ${ }^{11} \mathrm{~B}$ frequency of $272.631 \mathrm{MHz}$. Spectra were acquired by collecting 4096 transients using calibrated ${ }^{11} \mathrm{~B} \pi / 20$ pulses of $0.4 \mu \mathrm{s}$, a $625 \mathrm{kHz}$ sweep width, a spinning speed of $15 \mathrm{kHz}$, and a $2.0 \mathrm{~s}$ recycle delay. Time domain free induction decays were apodized with exponential functions corresponding to $150 \mathrm{~Hz}$ of Lorentzian broadening prior to Fourier transformation. ${ }^{11} \mathrm{~B}$ resonances were referenced to $\mathrm{BF} \mathrm{O}_{3} \mathrm{O}\left(\mathrm{CH}_{2} \mathrm{CH}_{3}\right)_{2}$ at $0 \mathrm{ppm}$ using $0.5 \mathrm{M} \mathrm{H} \mathrm{HO}_{3}$ as a secondary reference at $19.6 \mathrm{ppm}$. $\mathrm{N}_{4}$ ratios were calculated using $\mathrm{N}_{4} / \mathrm{N}_{\text {total }}$ values derived from resonance line fittings conducted in the Nuts software environment (Acorn NMR, Inc.). The chemical shift, line width, intensity, and percent Lorentzian were freely iterated until convergence was achieved. The primary uncertainty in the reported values for N4 arises from spectral noise levels, which are diminished by acquisition of a large number of transients for each spectrum. Estimation of the standard deviation in N4 is accomplished via a Monte Carlo algorithm in the Mathematica programming environment (Wolfram) that utilizes the root-mean-square deviation of a sample of random spectral noise to generate statistics from 5000 replications of fitted NMR spectra from a typical ${ }^{11} \mathrm{~B}$ spectrum in this study [70, 71]. Signal to noise values were comparable for all ${ }^{11} \mathrm{~B}$ data sets, and therefore a single representative spectrum was chosen to represent the data series. For all N4 values reported here, the error is $+/-0.5 \%$ or lower.

\subsection{Fe speciation: Mossbauer spectroscopy and chemical analysis}

Room temperature Mössbauer spectroscopy was performed at zero applied field. Samples were prepared by mixing approximately $60-70 \mathrm{mg}$ of glass powder with Vaseline in a Cu Mössbauer sample holder $(0.95 \mathrm{~cm}$ by $1.27 \mathrm{~cm})$. The holder was entirely filled with the sample mixture and sealed with tape. An oxygen impermeable polymer film (aluminized Mylar ${ }^{\circledR}$ ) was added as an outer seal on the both ends of the holder. Both the tape and polymer were snapped into the holder with rings made of carbonized-polyethyletherketone (PEEK) polymer to ensure tightness. Mössbauer spectra were collected at room temperature using a $75-\mathrm{mCi}$ (initial strength) ${ }^{57} \mathrm{Co} / \mathrm{Rh}$ source. The velocity transducer MVT-1000 (WissEL Electronik, Germany) was operated in a constant acceleration mode $(23 \mathrm{~Hz}, \pm 12 \mathrm{~mm} / \mathrm{s})$. An Ar$\mathrm{Kr}$ proportional counter was used to detect the radiation transmitted through the holder, and the counts were stored in a multichannel scalar (MCS) as a function of energy (transducer velocity) using a 1024 channel analyzer. Data were folded to 512 channels to give a flat background and a zero-velocity position corresponding to the center shift (CS or $\delta$ ) of a metal iron foil at room temperature. Calibration spectra were obtained with a $25-\mu \mathrm{m}$-thick $\alpha-\mathrm{Fe}(\mathrm{m})$ foil (Amersham, England) placed in the same position as the samples to minimize any errors due to changes in geometry. The Mössbauer data were modeled with the Recoil software using a Voigt-based structural filtering routine [72]. 
Chemical analysis was performed to asses $\mathrm{Fe}^{2+} / \mathrm{Fe}^{3+}$ redox ratios of the quenched glasses using a well-established colorimetric method which uses 1,10 phenanthroline to react with $\mathrm{Fe}^{2+}$ forming a strongly colored complex [73-75]. $200 \mu \mathrm{g}$ of vortexed glass powder (100 mesh) was placed in a $100 \mathrm{~mL}$ Teflon beaker and mixed with $0.5 \mathrm{~mL}$ of $\mathrm{H}_{2} \mathrm{SO}_{4}$ and $1.0 \mathrm{~mL}$ of $\mathrm{HF}$, diluted to $10 \mathrm{~mL}$ with deionized (DI) water $(18.2 \mathrm{M} \Omega)$, and stirred. $2.0 \mathrm{~mL}$ was then pipetted into a plastic beaker and diluted to $25.0 \mathrm{~mL}$ with $\mathrm{DI}$ water, and $\mathrm{pH}$ adjusted to $3.4+/-0.1$ with an ammonium acetate buffer solution. $5.0 \mathrm{~mL}$ of 1,10 phenanthroline solution was added to the beaker as the $\mathrm{pH}$ of solution was monitored, and further diluted to $50.0 \mathrm{~mL}$ with $\mathrm{DI}$ water and, if necessary, a drop of ammonium acetate. The solution was allowed to stand at room temperature for 10 minutes, then pipetted into a $1 \mathrm{~cm}$ quartz cuvette.

Transmittance was measured at $520 \mathrm{~nm}$ using a Cary 5000 (Agilent) UV-Vis NIR Spectrophotometry, and three iterations of the chemical digestion were performed and the values averaged to obtain the concentration of $\mathrm{Fe}^{2+}$ in the glass. Approximately $25 \mathrm{mg}$ of hydroxylamine, a mild reducing agent, was then added and mixed into the remaining sample, and heated on a hot plate at $100^{\circ} \mathrm{C}$ for 4 minutes, then removed and cooled to room temperature, approximately 20 minutes. Three iterations were measured and transmittance values at $520 \mathrm{~nm}$ were averaged to obtain the total iron concentration of the glass, since all Fe had been converted to $\mathrm{Fe}^{2+}$. Total ferric $\left(\mathrm{Fe}^{3+}\right)$ ion concentration was calculated by subtracting the experimentally determined total iron concentration from the ferrous $\left(\mathrm{Fe}^{2+}\right)$ iron concentration. For calibration, solutions of known Fe concentration ( $0.5 \mathrm{wt} \%$ to $50 \mathrm{wt} \% \mathrm{Fe})$ were measured with each set of samples and a reagent blank of $\mathrm{DI}$ water was used to zero the spectrophotometry.

\section{Results}

\subsection{Raman}

Both quenched and CCC glasses were investigated for each of the 6 nuclear waste glasses. Figure $3 a$ shows a comparison of the spectra for the quenched glasses in the HLW-E-ANa family $(24,25,26,4)$ and Figure $3 \mathrm{~b}$ shows the corresponding CCC glass spectra. Spectra for these quenched glasses show characteristic bands which vary with composition. The host glasses exhibit spectra dominated by borate bands, with some showing nepheline bands. These borate bands provide insight into the bulk glass chemistry as reflected in the coordinated borate structures (e.g., diborate, trigonal borate, boroxol rings, tetraborate, and di-pentaborate). In general borosilicates exhibit vibrational bands in four domains [76]: $300-500 \mathrm{~cm}^{-1}$ : mixed stretch and bend of Si-O-Si units; $550-850 \mathrm{~cm}^{-1}$ : ring breathing and NBO of B(III)-O of ring metaborate; $850-1250 \mathrm{~cm}^{-1}$ : T-O-T stretching of $Q^{n}$ species; $1250-1600 \mathrm{~cm}^{-}$ ${ }^{1}$ : $\mathrm{B}$ (III)-O related stretching in various coordinations. In general the quenched glass spectra consist of 6 regions as follows: (1) $300-450 \mathrm{~cm}^{-1}$; (2) $490-495 \mathrm{~cm}^{-1}$ (3) $540-550 \mathrm{~cm}^{-1}$; (4) $635-780 \mathrm{~cm}^{-1}$; (5) $900-$ $1000 \mathrm{~cm}^{-1}$; and (6) $1350-1375 \mathrm{~cm}^{-1}$. Detailed information on assignments for the regions of comparison in these glasses is shown in Electronic Annex Table A-1.

\subsubsection{Bands associated with nepheline}

Raman spectra from these glasses are composites of the crystalline phases and the intervening host glass. The thickness of the intervening glass was variable as the depth of crystals below the surface varied, therefore the intensity of nepheline bands varied. Spectra for the CCC glasses consisted of relatively well-resolved peaks in the low frequency regions $\left(\sim 100-300 \mathrm{~cm}^{-1}\right.$ and $\left.\sim 300-600 \mathrm{~cm}^{-1}\right)$ and $800-1200 \mathrm{~cm}^{-1}$. The strongest of these bands are superimposed on the broader host glass background. 
Standard spectra [77] of nepheline minerals have the bands as follows (sample reference number in parenthesis). Additionally, a broad band is centered $\sim 1370-1390 \mathrm{~cm}^{-1}$ and often a broad band $\sim 70$ $\mathrm{cm}^{-1}$.

- Nepheline (R040025) bands occur at 1082, 1034, 989, 610, 581, 498, 463, 422, 400, 351 and 267, 227 and $204 \mathrm{~cm}^{-1}$.

- Nepheline (R060581) bands occur at 1082, 1081, 993, 923, 610, 578, 496, 460, 418, 393, 353, 264, 226 and $203 \mathrm{~cm}^{-1}$.

- Nepheline (R090059) bands occur at 1099, 1087, 1037, 989, 969, 682, 550, 467, 411, 401, 349 and 267,206 and $159 \mathrm{~cm}^{-1}$.

When a typical crystallized glass is compared to a standard nepheline spectrum (R040025 from RRUF [77]), it can be seen that at least some of the structure in the $\left(100-300 \mathrm{~cm}^{-1}, 300-600 \mathrm{~cm}^{-1}\right.$, and $900-1100 \mathrm{~cm}^{-1}$ regions have similar vibrations to mineral nepheline (see Figure 4a), although there is some variability in measured nepheline mineral samples (see Electronic Annex Figure A-7). In particular, in this example, vibrations at 226,341,402,469,988,1037, and $1085 \mathrm{~cm}^{-1}$ are indicative of the nepheline crystal. In general, the $900-1100 \mathrm{~cm}^{-1}$ region vibrations are due to the Si-O-T stretches, where the tetrahedrally coordination ion $\mathrm{T}=\mathrm{Al}, \mathrm{B}(\mathrm{IV})$, or $\mathrm{Si}$, but for nepheline this is Si-O-Al(IV). It is not surprising that the 13 glass exhibits the closest spectrum to nepheline, as it has the highest crystal fraction of the glasses investigated ( $\sim 0$ vol\%). The 5-1 glass, while being compositionally rather different than the others, exhibits similar Raman bands to the other glasses (Figure 5).

\subsubsection{Bands associated with boron speciation in glass}

Borate bands were usually broader than the bands attributable to crystalline nepheline. The exception to this generalization was polarized borate bands occurring as very sharp peaks. These sharp peaks represent borate vibrationally isolated from the host glass matrix, such as six coordinate boroxol rings. These polarized peaks occurred at different energies in the different glasses. For example; very sharp boroxol ring vibrations occur at; $987 \mathrm{~cm}^{-1}(5-1), 966 \mathrm{~cm}^{-1}(13), 961 \mathrm{~cm}^{-1}(26), 949 \mathrm{~cm}^{-1}$ (4), and 947 $\mathrm{cm}^{-1}(25)$.

The predominant borate band in most CCC glasses occurred between $710-705 \mathrm{~cm}^{-1}$, and as seen above this is not associated with nepheline. A comparable band at $\sim 685 \mathrm{~cm}^{-1}$ occurred in the quenched glasses. These bands were broad single-mode bands in the CCC spectra. The $685 \mathrm{~cm}^{-1}$ band from the quenched glass spectra was also broad and usually had a strong shoulder at $\sim 645 \mathrm{~cm}^{-1}$. The 710 to 705 $\mathrm{cm}^{-1}$ band represents chain metaborates that only persist in the CCC glasses, presumably because the longer cooling period of the CCC glasses allows these more highly coordinated species to organize or, alternatively, the melt chemistry changes on crystal precipitation favor these species. The $685 \mathrm{~cm}^{-1}$ band seen in the quenched glasses may be attributed to ring metaborates which possess lower degrees of order than chain metaborates. These bands may merely reflect the effect of quenching period on more highly ordered borate species. The presence of chain metaborate bands is therefore not an indicator for when nepheline will form in the host glass. It does appear, however, that these chain metaborate bands are signature of the residual glass phase after crystallization, along with the trigonal borate signature (observed as two humps at 1387 and $1287 \mathrm{~cm}^{-1}$ characteristic of this boron moiety).

The assignment of the $700-710 \mathrm{~cm}^{-1}$ Raman band is of primary importance for the current study so other interpretations should be considered. A band at $711 \mathrm{~cm}^{-1}$, shown to be present in La-B-O glasses with $>15$ mol\% $\mathrm{Al}_{2} \mathrm{O}_{3}$, was assigned to aluminate species such as $\mathrm{Al}^{-} \mathrm{O}^{-}$or $\mathrm{Al}-\mathrm{O}-\mathrm{B}$ stretch [25]. Others have proposed that this peak could be due to high-coordinated (5- or 6-coordinated) aluminum, but NMR studies (including this one) have not shown aluminum coordination other than four when this band was 
observed [78]. It has been suggested that formation of $\mathrm{Al}(\mathrm{V})$ and $\mathrm{NBO}$ is decoupled in the metaluminous region [79]. A more satisfying explanation is that of "excess $\mathrm{Al}$ " around and beyond the metaluminous ( $\mathrm{Na} / \mathrm{Al}^{1}$ ) composition [78]. Others have claimed that the Raman signature in question is due to 3 coordinated oxygen surrounded by tetrahedral cations at least one of which is $\mathrm{Al}$ [80]. All the glasses considered here are peraluminous $(\mathrm{Na} / \mathrm{Al}<1)$ if only $\mathrm{Na}$ is considered as the charge compensating cation for aluminum. Therefore, assuming that nepheline precipitation removes equimolar $\mathrm{Na}$ and $\mathrm{Al}$, the residual glass remains peraluminous. However, given that there are more $B$ atoms than $\mathrm{Al}$ atoms in these glasses (see Section 4.3), and that most of them are B(III) (see Table II), it seems more likely that the Raman bands from the glasses in this study are due to metaborate.

\subsection{NMR}

The following section is organized as follows. For each nucleus, first a discussion is made of the quenched versus CCC glass spectra. Subsequently, the spectra of those glasses crystalizing nepheline are compared to the standard "nepheline glass" and nepheline mineral specimens. The nuclei will be discussed in the following order: ${ }^{23} \mathrm{Na},{ }^{27} \mathrm{Al},{ }^{29} \mathrm{Si}$, and ${ }^{11} \mathrm{~B}$.

\subsection{1 ${ }^{23} \mathrm{Na}$ direct polarization}

The ${ }^{23} \mathrm{Na}$ NMR spectra for the quenched versus CCC glasses are shown in Figure 6 . The quenched glasses exhibit a broad featureless Gaussian line with a center of mass at approximately $-5 \mathrm{ppm}$, indicative of a heterogeneous amorphous environment at the local level of the $\mathrm{Na}$ atom, while the majority of the CCC glasses display an additional resonance. Nepheline has two distinct alkali sites, both of which can be filled by sodium in low potassium compositions [42]. Sample 13-CCC displays resonances at -5 and $-20 \mathrm{ppm}$, which are consistent with the sodium (oval channel [37]) and potassium (hexagonal channel [37]) sites in nepheline, respectively [81]. The $-20 \mathrm{ppm}$ resonance is evident in the CCC samples of 25, 26, and 4, although clearly to a lesser extent than 13 . The aforementioned glasses crystallized 14-38 vol\% nepheline [68]. Similarly, the spectrum of sample 5-1-CCC may be interpreted as emerging nepheline resonances, but this cannot be determined from the ${ }^{23} \mathrm{Na}$ data alone, and it is not surprising that this signature is particularly weak given the crystallization of only 5 vol\% nepheline [67]. Spin lattice relaxation for several representative samples are shown in Table 3 . The $T_{1}$ relaxation exhibited by the resonances at $-20 \mathrm{ppm}$ of the CCC treated samples may be explained by an increase in crystallinity within the nepheline phase as compared to the parent material. It is interesting to note the change in $\mathrm{T}_{1}$ as a function of CCC treatment, implying an increase in local order around the ${ }^{23} \mathrm{Na}$ remaining in the glass phases.

Figure 6 also shows the comparison of the ${ }^{23} \mathrm{Na}$ signal of CCC samples with the standard mineral nepheline and the pure sodium nepheline glass. It is evident that the standard glass shows a broad distribution of $\mathrm{Na}$ sites with a center of mass near the normal nepheline $\mathrm{Na}$ channel, $-5 \mathrm{ppm}$. Interestingly, it does not appear to have an obvious -20 ppm component, unlike some of the CCC glasses, and in particular 13. The quenched glasses in Figure 6 show that the main $\mathrm{Na}$ site in glass is similar to the Na site in nepheline, in that it is more like the center of a distorted oval consisting of sixmembered rings of connected tetrahedra, rather than the center of a symmetrical hexagon of sixmembered rings such as the typical $\mathrm{K}$ site in nepheline. The Na site in mineral nepheline shows no -20 ppm component, indicating that this site is filled with another atom, likely $\mathrm{K}$. The unidentified peak 10 ppm is likely due to an impurity (another phase) since the mineral specimen was not pure nepheline as has already been noted in section 2.1 . 


\subsection{2 ${ }^{27} \mathrm{Al}$ direct polarization}

The ${ }^{27} \mathrm{Al}$ NMR spectra for the quenched versus CCC glasses are shown in Figure 7. Quenched samples exhibit a broad, featureless line centered between 58 and 60 ppm. Upon CCC, HLW-E-ANa-26 and IWL-HAC5-1 exhibit a subtle high frequency shoulder indicative of an additional resonance, and HLW-E-ANa-13(3Al-3Si) narrows and exhibits what may be construed as two resonances.

Figure 7 also shows the comparison of the ${ }^{27} \mathrm{Al}$ signal of CCC samples with the standard mineral nepheline and the pure sodium nepheline glass. Resonances at $\sim 64$ and $\sim 61 \mathrm{ppm}$ shown in the mineral sample are indicative of the two sites of ${ }^{27} \mathrm{Al}$ in crystalline nepheline [82], which have been called $\mathrm{T}_{G}$ (general site with two $\mathrm{Na}$ and one $\mathrm{K}$ neighbor) and $\mathrm{T}_{\mathrm{S}}$ (special site with three Na neighbors) [42]. The pure sodium nepheline glass shows a broad featureless line centered $\sim 60 \mathrm{ppm}$. Since the waste glasses do not contain much potassium $\left(<1 \mathrm{wt} \% \mathrm{~K}_{2} \mathrm{O}\right)$, the presence of two sites in the CCC glasses are rather indicative of $A l$ in the tetrahedral sites which are $A$ ) bordered only by oval rings ( $T_{S}$ which includes $T(1)$ and $T(2)$, bordered by three Na channels) and B) bordered by two oval rings and one hexagonal ring (the one normally containing $K$ ) ( $T_{G}$ which includes $T(3)$ and $T(4)$, bordered by two Na channels and one $K$ channel) $[37,40,49]$. NMR investigations of mixed kalsilite $\left(\mathrm{KAlSiO}_{4}\right.$, which has only hexagonal channels [37]) and nepheline suggest that the lower frequency ${ }^{27} \mathrm{Al}$ resonance $\sim 60 \mathrm{ppm}$ is associated with the hexagonal channels (i.e., $\mathrm{T}_{\mathrm{G}}$ or $\mathrm{T}(3)$ and $\mathrm{T}(4)$, most likely the latter in the case of Al) [42]. For the 13-CCC sample, and to a lesser degree in 26-CCC and 5-1-CCC, a high frequency shoulder is evident, suggesting speciation of the Al site. Note that the peak in quenched and CCC samples and pure sodium nepheline glass is at lower frequency, suggesting that the quenched structure has Al sites with local symmetry more like $\mathrm{T}_{\mathrm{G}}$ on average (i.e., with nearby hexagonal channels with some distribution), whereas crystallization promotes the formation of additional Al sites (i.e., $\mathrm{T}_{\mathrm{s}}$ ) connecting squashed channels in which two sodium atoms sit.

\subsection{3 ${ }^{29}$ Si direct polarization $\mathrm{w} /{ }^{1} \mathrm{H}$ decoupling}

The ${ }^{29} \mathrm{Si}$ NMR spectra for the quenched versus CCC glasses are shown in Figure 8. Quenched glasses exhibit very broad, featureless lines indicative of a highly disordered system, with a shifting center of mass primarily resulting from incorporation of Al and B into the network. The center of mass for quenched glasses range from $-86 \mathrm{ppm}$ to $-89 \mathrm{ppm}$. In pure sodium silicate glasses the degree of polymerization is reflected in the chemical shift, where the fully polymerized silicon species $\left(Q^{4}\right.$ tetrahedra with four bridging oxygens) falls in the range of -100 to $-110 \mathrm{ppm}$, and with each subsequent non-bridging oxygen added there is a concomitant high frequency shift (decrease of $10 \mathrm{ppm}$ ) associated with the corresponding silicon resonance $[83,84]$. However, it has been shown that the addition of boron or aluminum near-neighbors (e.g., $\mathrm{B}(\mathrm{IV})-\mathrm{O}-\mathrm{Si}$ or $\mathrm{Al}(\mathrm{IV})-\mathrm{O}-\mathrm{Si}$ ) results in a high frequency shift relative to the pure silicate species of 5 and $10 \mathrm{ppm}$, respectively. For boron incorporation, this frequency shift is due to the decreased bond angle and increased concentration of electrons on the Si-O side of the bond relative to the $\mathrm{B}(\mathrm{IV})-\mathrm{O}$ side of the bond [83]. Upon CCC, clear changes relative to the as quenched glasses are evident in 13, 26, and 5-1, with the most dramatic effect exhibited by 13.

Figure 8 also shows the comparison of the ${ }^{29} \mathrm{Si}$ signal of CCC samples with the standard mineral nepheline and the pure sodium nepheline glass. In mineral nepheline, peaks are observed at -85 and -88 ppm, and shoulders at -92 and possibly -102 ppm are evident. According to Stebbins et al [44], the assignments of the main peaks should be to the two Si framework sites $T_{S}$ and $T_{G}$ at -85 and -88 ppm, where each $\mathrm{Si}$ atom is surrounded by four $\mathrm{Al}$ atoms (i.e., perfect Al-Si ordering or $\mathrm{Q}^{4}(4 \mathrm{Al})$ ). The center of mass location of the broad ${ }^{29} \mathrm{Si}$ line in sodium nepheline glass is $\sim-85 \mathrm{ppm}$, and the $-88 \mathrm{ppm}{ }^{29} \mathrm{Si}$ resonance is assigned to the $\mathrm{T}_{\mathrm{G}}$ silicon site (with two $\mathrm{Na}$ and one $\mathrm{K}$ neighbors) while the $-85 \mathrm{ppm}{ }^{29} \mathrm{Si}$ 
resonance is assigned to the $T_{S}$ silicon site (with three Na neighbors). This assignment is based on the NMR investigations of mixed kalsilite and nepheline where the $-88 \mathrm{ppm}$ resonance arises from the ${ }^{29} \mathrm{Si}$ site with hexagonal channels in proximity, $\mathrm{T}(3)$ or $\mathrm{T}(4)$ sites, most likely the former in the case of Si. Note that the center of mass for ${ }^{29} \mathrm{Si}$ is closer to that expected for the "special" site in nepheline, albeit with a very broad distribution, in contrast to the ${ }^{27} \mathrm{Al}$, which has a center of mass more similar to the "general" site in nepheline. The -85 and -88 ppm resonances are clearly exhibited in CCC samples of 13 , and to a lesser extent 5-1 and possibly 26 . The weaker resonance in mineral nepheline at $-92 \mathrm{ppm}$ has been assigned to $\mathrm{Si}$ atoms with only 3 surrounding $\mathrm{Al}$ atoms (i.e., $\mathrm{Q}^{4}(3 \mathrm{Al})$ ) while that at $-102 \mathrm{ppm}$ has been assigned to $\mathrm{Si}$ atoms with no surrounding $\mathrm{Al}$ atoms $\left(\mathrm{Q}^{4}(\mathrm{OAI})\right)$, and these defects in the perfect nepheline structure have been ascribed to stacking faults at domain boundaries in the crystal [44].

\subsection{4 ${ }^{11} \mathrm{~B}$ direct polarization}

The ${ }^{11} B$ NMR spectra for the quenched versus CCC glasses are shown in Figure 9. Characteristic signatures for tetrahedral boron, $\mathrm{B}(\mathrm{IV})$, are seen at $5 \mathrm{ppm}$ and for trigonal boron, $\mathrm{B}(\mathrm{III})$, at $15 \mathrm{ppm}$ [85]. Previous studies using triple quantum magic angle spinning (3QMAS) NMR of ${ }^{11} \mathrm{~B}$ and ${ }^{17} \mathrm{O}$ in alkali borosilicate glasses have shown that the $B(I V)$ peak can be further subdivided into $B(I V)-[0 B, 4 S i]$ ( -5 ppm), $B(I V)-[1 B, 3 S i](\sim 0 \mathrm{ppm}), B(I V)-[2 B, 2 S i](\sim 5 p p m)$ and the $B(I I I)$ peak can be further subdivided into non-ring $B(\mathrm{III})(\sim 14 \mathrm{ppm})$ and ring $B(\mathrm{III})(\sim 18 \mathrm{ppm})$, distinguished by the next nearest neighbors in the $B(I V)$ tetrahedral being the boroxol ring or trigonal non-ring coordinated $B(I I I)$ [86]. Based on quadrupolar coupling constants $\left(C_{q}\right)$, quadrupolar asymmetry parameters $(\eta)$, and the isotropic chemical shift empirically derived for simplified alkali borosilicate glasses [85], the apparent center of mass was calculated for a range of $B(I I I)$ and $B(I V)$ species. A comparison was made to the peak maxima of the ${ }^{11} B$ resonances in Figure 9. The calculated values that matched the experimental chemical shifts of $\sim 15$ and $\sim 0$ ppm are consistent with $\mathrm{B}(\mathrm{III})$ ring structures and $\mathrm{B}(\mathrm{IV})-[1 \mathrm{~B}, 3 \mathrm{Si}]$ [85]. However, it is entirely possible that other species are present in these structures but are not discernible due to the broadness of these resonances $(>4 \mathrm{ppm})$. Other authors $[26,86,87]$ have performed peak deconvolution of ${ }^{11} \mathrm{~B}$ spectra to assess the relative frequency of these units, but we only describe them qualitatively here due to the lack of high resolution MQMAS data. The broad featureless ${ }^{11} \mathrm{~B}$ resonances preclude specific ${ }^{11} \mathrm{~B}$ speciation, e.g. ${ }^{11} \mathrm{~B}$ with NBO. The broad Gaussians most likely arise due to the $\sim 3$ wt $\% \mathrm{Fe}_{2} \mathrm{O}_{3}$ and the heterogeneity of ${ }^{11} \mathrm{~B}$ sites within the glass.

As can be seen from Table 3, over half of the boron sites are $B(I I I)$ in all cases. A large increase in the number of $B(I V)$ sites known as $N 4$, defined as integrated area $B(I V) /[B(I I I)+B(I V)]$, is seen in the $C C C$ relative to the quenched glass in 13 , increasing from $19 \%$ to $47 \% \mathrm{~B}(\mathrm{IV})$ upon formation of 38 vol\% nepheline. Smaller increases are evident in 26 and 5-1.

\subsection{Fe speciation}

Iron redox analysis results on quenched glasses are shown in Table 4. Spectrochemical analysis was performed in triplicate on each glass to determine $\mathrm{Fe}^{2+} / \mathrm{Fe}^{3+}$ ratios. The calculated total iron weight\% for each glass was slightly less than that reported in Table 1 for the target composition. The loss of iron can be attributed to inconsistent sampling when the glass was powdered. All glasses analyzed showed a $\mathrm{Fe}^{2+} / \mathrm{Fe}^{3+}$ ratio between 0.06 and 0.04 with an average standard deviation of approximately 0.01 . These values are consistent with that obtained for similar glass compositions melted under similar conditions, indicating $\sim 94-96 \% \mathrm{Fe}^{3+}$ ions $[27,31]$.

Room temperature Mössbauer spectra were collected at zero magnetic field for 24, 26, 13, and 5-1, both quenched and CCC glasses, and results are summarized in Electronic Annex Fig A.8 - Fig A.12. Spectra of the quenched glasses measured are all similar. A good fit for $26 \mathrm{Q}$ sample, as an example (see 
Figure 10a), is realized by inclusion of a central doublet/superparamagnetic Fe and a broad sextet (distribution of sextets) as components in the modeled fit. The 26-Q and the 26-CCC sample (see Figure $10 \mathrm{~b})$ show these features. The doublet and very broad sextet feature are similar to those noted for $5 \mathrm{~nm}$ "nanomaghemite" $\mathrm{Y}-\mathrm{Fe}_{2} \mathrm{O}_{3}$ [88]. However, it is not possible to unambiguously assign these features to nanomaghemite since small particle "nanomagnetite" $\mathrm{Fe}_{3} \mathrm{O}_{4}$ also displays broad features at room temperature [88], and the features should probably be assigned to small-particle magnetite/maghemite/non-stoichiometric magnetite. Low temperature Mössbauer data would be required to fully assign these peaks

After CCC heat treatment, the Mössbauer spectra are radically changed. The various glass CCC spectra are again similar to one another, but there is strong evidence of one or more crystalline ordered magnetic Fe phases as evidenced by the presence of well-defined sextet features, in addition to the broad sextet feature and the Fe(III) doublet present in the quenched glass. Modeling of the 26-CCC spectrum, as an example, (see Figure $10 \mathrm{~b}$ and Table 5) suggests that multiple Fe-containing crystalline phases are present. The well-defined sextet features are characteristic of octahedral and tetrahedral sites in large-particle $(>5 \mathrm{~nm}$ ) maghemites [88]. The derived Mössbauer parameters of the sextets (Table 5) are similar to those reported for maghemite by Da Costa et al [89]. The essential difference between the $Q$ and CCC samples are the presence of "large particle" maghemite in the CCC samples.

$X$-ray diffraction of these same CCC glasses as reported previously $[67,68]$ identified $1-4$ vol\% of magnetite $\mathrm{Fe}_{3} \mathrm{O}_{4}$ in these glasses. However, it is known that $\mathrm{Fe}_{3} \mathrm{O}_{4}$ is very difficult to distinguish by XRD from maghemite due to the very subtle changes in unit cell sizes [90]. Additionally, waste glasses often have mixed transition metal spinels $[5,33]$ which cannot readily be distinguished by XRD, only by electron microprobe. There is no immediate evidence from room temperature zero field Mössbauer suggesting $\mathrm{Fe}^{2+}$, and the iron redox suggests low fractions of it, thus it is likely that the crystalline species observed in XRD is maghemite (containing only $\mathrm{Fe}^{3+}$ ) and not magnetite (containing $\mathrm{Fe}^{2+}$ and $\mathrm{Fe}^{3+}$ ). The presence of other spinels cannot be ruled out, but the fact that two sets of sextets are present in CCC samples suggests Fe in both spinel sites.

There is good reason for considering the relationship between spinel (such as magnetite and maghemite) precipitation and nepheline crystallization. Spinel crystallization occurs in many nuclear waste glasses and often with nepheline. Some have argued that spinel crystals may provide nucleation sites for nepheline crystallization from the sodium aluminosilicate melt [33], and many micrographs have shown spinel crystals inside larger nepheline crystals (e.g., Fig 15 in [7], Fig 7 in [9], Fig 3.11 and 3.34 in [91]).

\section{Discussion}

\subsection{Conventional descriptions of the glass-forming network}

When $\mathrm{Al}^{3+}$ or $\mathrm{B}^{3+}$ substitutes in a $\mathrm{Si}^{4+}$ tetrahedral site, charge balance requires that another ion compensate for the net negative charge of the tetrahedron. This is accomplished by local alkali $(1+)$, alkaline earth $(2+)$, or rarely aluminum or lanthanide $\left(3^{+}\right)$cations. It is generally accepted that linkages between tetrahedral sites consisting of two charged sites (i.e., $\mathrm{B}(\mathrm{IV})$ or $\mathrm{Al}(\mathrm{IV})$ ) are unlikely in glass due to the high local charge density. This "rule" precludes the common occurrence of AI(IV)-O-B(IV), B(IV)-O$\mathrm{B}(\mathrm{IV})$, and $\mathrm{Al}(\mathrm{IV})-\mathrm{O}-\mathrm{Al}(\mathrm{IV})$ linkages. It also denotes preferred linkages requiring no charge compensation such as $\mathrm{Si}-\mathrm{O}-\mathrm{Si}, \mathrm{B}(\mathrm{III})-\mathrm{O}-\mathrm{B}(\mathrm{III})$, or $\mathrm{B}(\mathrm{III})-\mathrm{O}-\mathrm{Si}$ or linkages involving $\mathrm{Si}$ or $\mathrm{B}(\mathrm{III})$ requiring compensation on the other end-member of the bond: e.g., $\mathrm{Al}(\mathrm{IV})-\mathrm{O}-\mathrm{Si}, \mathrm{B}(\mathrm{IV})-\mathrm{O}-\mathrm{Si}, \mathrm{Al}(\mathrm{IV})-\mathrm{O}-\mathrm{B}(\mathrm{III})$, or $\mathrm{B}(\mathrm{IV})-\mathrm{O}-\mathrm{B}(\mathrm{III})$. This has been called the "aluminum avoidance" [42, 92] or "boron avoidance" [93] rule. This rule appears 
generally true in alumino-boro-silicate glasses unless there is a large concentration of high field-strength cations to compensate both tetrahedra [94] where higher-coordinated aluminum as $\mathrm{Al}(\mathrm{V})$ and $\mathrm{Al}(\mathrm{VI})$, are often observed [12]. Though this bonding topology can be inferred from cation NMR analyses a richer and more descriptive understanding of these bonding statistics can only be obtained by simultaneous investigation of the oxygen by ${ }^{17} \mathrm{O}$ MAS and 3QMAS spectra of isotopically enriched glasses. This is particularly true when non-bridging oxygens are taken into account for each of these links, and the effect of modifier cations has been shown to be distinctive. Higher field strength cations tend to result in bond speciation closer to a random mixing model than a chemically ordered (avoidance) model, both with alumino-boro-silicate glasses [12] and alumino-borate glasses [24]. The spectrum of extremes from phase separation (pure chemical ordering) to random ordering has been referred to as the "interdispersion" of the glass network [95].

General trends in speciation are fairly well understood for glasses consisting of two network formers (including aluminum). However, the simultaneous presence of $\mathrm{Al}, \mathrm{B}$, and $\mathrm{Si}$ results in very complex speciation as can be appreciated from the above possibilities. Phase separation ("unmixing") is well known in boro-silicate glasses, occurring at the nanoscale in certain cases such as in low sodium glasses [93]. These glasses consist of a silicate-rich phase and a sodium-borate-rich (i.e., $\mathrm{B}(\mathrm{III}))$ phase [93]. The fraction of boroxol ring $B(I I I)$ increases with increasing boron content in boro-silicate glasses [95]. Additionally, it has been shown that $B(I V)$ and non-ring $B(I I I)$ tend to mix with silicate, while ring $B(I I I)$ is primarily associated with borate groups. Phase separation induced by heat treatment, as evident from visible changes does not seem to significantly change N4, but some non-ring $B(I I I)$ changes to ring $B(I I I)$, thus separating from the silicate part of the glass [96].

The effect of higher field-strength cations in alumino-boro-silicate glasses appears to promote formation of NBO, conversion of boron to $\mathrm{B}(\mathrm{III})$, and sometimes a fraction of $\mathrm{Al}(\mathrm{V})$ [12]. High field strength modifiers (e.g., $\mathrm{Ca}$ ) are also known to concentrate charge on $\mathrm{NBO}$ and convert $\mathrm{B}(\mathrm{IV})$ to $\mathrm{B}(\mathrm{III})$ [13]. Higher coordinated aluminum is common in glasses with high field-strength alkaline earth cations such as Be [97], Mg [98], Ca [99, 100], and Ba [79]. Deviation from the avoidance principle in aluminosilicate glasses is most apparent in ${ }^{17} \mathrm{O}$ spectra of glasses near the metaluminous composition (moles of $\mathrm{Na} / \mathrm{Al}$ 1) [101]. The studied glasses 24, 25, and 26 are metaluminous, however no higher coordinated Al was observed in these glasses which contain significant fractions of $\mathrm{Li}_{2} \mathrm{O}$ but little alkaline earth or lanthanide modifiers.

\subsection{Distribution of alkali in the network}

Darab et al. [21] created a model to assess the distribution of $\mathrm{Na}$ in an alumino-boro-silicate glass when NMR data was available to assess the fraction of $\mathrm{AI}(\mathrm{IV})$ and $\mathrm{B}(\mathrm{IV})$. In this model several quantities must be estimated. First, $\mathrm{f}_{\mathrm{Na}}$ is the fraction of $\mathrm{Na}$ atoms which are available for the network after all the $\mathrm{Al}(\mathrm{IV})$ has been compensated. All but one of the glasses considered in this study, has insufficient $\mathrm{Na}$ to compensate $\mathrm{Al}(\mathrm{IV})$ (i.e., the glasses are peraluminous). In lieu of $\mathrm{Na}$ alone, we instead take the quantity of the total alkali ( $\mathrm{Li}, \mathrm{Na}, \mathrm{K}$, and $\mathrm{CS}$ ) as the fraction of network modifying cations $\left(\mathrm{f}_{\mathrm{Alk}}\right)$. The current glasses contain significant $\mathrm{Li}$ concentrations and very little $\mathrm{K}$ and no $\mathrm{Cs}$. The fraction of residual alkali after compensating $\mathrm{Al}(\mathrm{IV})$ then becomes:

$$
f_{A l k}=([L i]+[\mathrm{Na}]+[\mathrm{K}]+[\mathrm{CS}]-[\mathrm{Al}]) /([\mathrm{Si}]+[\mathrm{B}]) .
$$

where the quantities in brackets are molar concentrations of atoms. The fraction of boron sites in the borosilicate network remaining, making no assumptions about boron coordination, is simply:

$$
f_{B}=[B] /([S i]+[B]) .
$$


The fraction of $B(I V)$ sites $\left(f_{B 4}\right)$, then, should be related to the fraction of available alkali $\left(f_{A \mid k}\right)$, the fraction of the remaining sites which have boron $\left(f_{B}\right)$, and a partitioning coefficient that accounts for distribution between $\mathrm{Si}$ and $\mathrm{B}\left(\mathrm{k}_{\mathrm{B}}\right)$ :

$$
f_{B 4}=k_{B} f_{A l k} f_{B} \text {. }
$$

From NMR the number of $A$ l sites which are $A I(I V)$ is known (in this case 100\%) and the number of $B$ sites which are $\mathrm{B}(\mathrm{IV})$ are known (N4=B(IV)/[B(IV)+B(III)]), $\mathrm{f}_{\mathrm{B} 4}$ can be computed as:

$$
\mathrm{f}_{\mathrm{B} 4}=\mathrm{N} 4 *[\mathrm{~B}]=\mathrm{N} 4 * 2 *\left[\mathrm{~B}_{2} \mathrm{O}_{3}\right] .
$$

Taking measured values of $\mathrm{N} 4$ and calculated values from composition, one can plot Eq. 3 and do a linear fit to determine $k_{B}$, setting the intercept to zero. For the 5 glasses in question here (glass 5-1 appeared an outlier and was a substantially different composition), this analysis gives $a k_{B}$ of 0.90 with a reasonable (but not outstanding) $R^{2}$ of 0.77 . With this, now the fraction of alkali partitioning to the various possibilities can be further computed, again following Darab et al [21] modified to assume all alkali contribute.

$$
\begin{aligned}
& f_{A l k}^{A l(I V)}=[A I] /[A l k] \\
& f_{A l k}^{B(I V)}=k_{B}^{*}\left(1-f_{A l k}^{A l(I V)}\right) /(1+[S i] /[B]) \\
& f_{A l k}{ }^{N B O}=1-f_{A l k}^{A l(I V)}-f_{A l k}^{B(I V)}
\end{aligned}
$$

where the $\mathrm{f}_{\mathrm{Alk}}$ coefficients show the fraction of the alkali associated with $\mathrm{Al}(\mathrm{IV}), \mathrm{B}(\mathrm{IV})$, and non-bridging oxygens (NBOs), respectively. Note that it is not explicit in this analysis where the NBOs are, whether on $\mathrm{Al}(\mathrm{IV}), \mathrm{B}(\mathrm{IV}), \mathrm{B}(\mathrm{III})$, or Si(IV). Implicit in this analysis is that alkali partition first to $\mathrm{Al}(\mathrm{IV})$, then to $\mathrm{B}(\mathrm{IV})$, then to NBO. Additionally, it can be tested whether the alkaline earth atoms also contribute, where Eq. 1 is modified to include $\mathrm{Mg}+\mathrm{Ca}+\mathrm{Sr}+\mathrm{Ba}$, however in the current glasses only $\mathrm{Ca}$ has significant concentration. It is assumed that each alkaline earth is equivalent to two alkali. If this $f_{A I k+A E}$ (analogous to Eq. 1 ) is propagated through to Eq. 3 , and one plots $f_{B 4}$ versus $k_{B} f_{A l k+A E} f_{B}$ one finds an extremely poor linear fit, hence it is concluded that the alkaline earth atoms in the current glasses do not contribute to network breaking in a way that the alkali do. This is a similar conclusion reached by Darab et al. [21]. Results of these glass analyses are shown in Table 6 . Note that the $60-75 \%$ of alkali are associated with $\mathrm{Al}(\mathrm{IV}), 10-18 \%$ with $\mathrm{B}(\mathrm{IV})$, and $15-26 \%$ with NBO by this model. This model therefore predicts a significant fraction of NBO in these glasses, though it does not explicitly assume anything about where the NBOs are located (e.g., on $\mathrm{B}(\mathrm{III})$, Si(IV), $\mathrm{Al}(\mathrm{IV})$, or $\mathrm{B}(\mathrm{IV})$ ).

\subsection{Alternative network representation and residual glass after crystallization}

One instructive investigation of the glass composition is to look at the Si:Al:B ratios in the starting glasses normalized to a single $\mathrm{Si}$ atom. This data is shown in Table 8. For example, the 13 glass can be described as 1.00:0.92:0.80, thus the glass has more Si atoms than Al or $\mathrm{B}$, and more Al than $\mathrm{B}$. If we further assume that all the $\mathrm{Si}$ is 4-coordinated, all the $\mathrm{Al}$ is 4-coordinated (since there is no ${ }^{27} \mathrm{Al}$ indication otherwise), and the 4-coordinated $B$ is determined from the $\mathrm{N} 4$, we can arrive at a relationship of glassformers in tetrahedral coordination which is 1.00:0.92:0.15 for $\mathrm{Si}(\mathrm{IV}): \mathrm{Al}(\mathrm{IV}): \mathrm{B}(\mathrm{IV})$. This tells us that the primary tetrahedron needing compensation is $\mathrm{Al}$ and the appropriate metric for understanding the compensation is $\mathrm{Na} / \mathrm{Al}$, which for this glass is 0.86 , indicating a peraluminous composition. It must then be assumed that the balance of the charge compensation in this glass is coming from $\mathrm{CaO}(7.05 \mathrm{~mol} \%)$, $\mathrm{MgO}(0.38 \mathrm{~mol} \%), \mathrm{Li}_{2} \mathrm{O}(7.13 \mathrm{~mol} \%)$, and $\mathrm{K}_{2} \mathrm{O}$ (0.48 mol\%). 
Additionally, we can estimate the composition of the residual glass after crystallization of nepheline. For example, assuming no other crystallization products of consequence and the fraction of nepheline (as $\mathrm{NaAlSiO}_{4}$ ) in HLW-E-ANa-13(3AI-3Si) produced upon CCC was $38 \mathrm{wt} \%$ as was measured by XRD. We then subtract the moles of $\mathrm{NaAlSiO}_{4}$ produced by the crystallization and arrive at a residual glass composition which can be expressed as 1.00:0.84:1.65 for Si:Al:B, or taking the ${ }^{11} \mathrm{~B}$ NMR data for N4 for the CCC sample, 1.00:0.84:0.78 for Si(IV):AI(IV):B(IV) (see Table 7). Thus even though the majority of the boron in the residual glass network is $B(I I I)$, a substantial amount is $B(I V)$ when compared to the amount of Si(IV) and $\mathrm{Al}(\mathrm{IV})$. The remaining $\mathrm{Na} / \mathrm{Al}$ ratio in the glass is 0.68 , or more peraluminous than the starting glass. Additionally, the residual glass is enriched in $\mathrm{CaO}$ and $\mathrm{Li}_{2} \mathrm{O}$ with respect to the starting glass, presumably making the network more depolymerized (more NBO) than is apparent from the $\mathrm{Na} / \mathrm{Al}$ ratio. Note that these higher field strength cations ( $\mathrm{Li}$ and $\mathrm{Ca}$ ) apparently have not contributed much to the creation of $B(I I I)$ from $B(I V)$ as suggested in the literature, and rather the crystallization of nepheline has resulted in an increase in B(IV), all of which is presumably in the residual glass. Though we cannot be certain without more sophisticated NMR studies, one can assume that the large amount of $\mathrm{B}(\mathrm{III})$ in the residual glass must be either non-ring and connected to the silicate network, or ring and separated from the residual glass (essentially phase separated). From a simple accounting standpoint, it would seem that all of the $\mathrm{Na}$ and at least some of the other alkali and alkaline earth cations would have to be used to charge compensate the AI(IV) and B(IV). The non-ring $B(I I I)$ species, if they exist, may be placed in the network such that they facilitate the AI(IV), B(IV) mutual avoidance.

As a counter example to this one, we consider 24 , which did not have any nepheline precipitation but which did change its boron speciation after CCC. By the same analysis then, this glass starts with a Si:Al:B ratio of 1.00:0.83:0.98 and 1.00:0.83:0.27 for $\mathrm{Si}(\mathrm{IV}): \mathrm{Al}(\mathrm{IV}): \mathrm{B}(\mathrm{IV})$. Without aluminosilicate crystallization, the Si:Al:B does not change, but the speciation changes to 1.00:0.83:0.23 for $\mathrm{Si}(\mathrm{IV}): \mathrm{AI}(\mathrm{IV}): \mathrm{B}(\mathrm{IV})$. The amount of $\mathrm{B}(\mathrm{IV})$ actually decreases in favor of $\mathrm{B}(\mathrm{III})$, such as is normally assumed to occur with the addition of high field strength modifier cations. The only crystallization observed in this glass was the formation of a spinel, which had previously been tentatively identified as $\mathrm{Fe}_{3} \mathrm{O}_{4}$ [68] but according to Mössbauer combined with XRD is likely $\mathrm{\gamma}-\mathrm{Fe}_{2} \mathrm{O}_{3}$ (maghemite). It is instructive, then, to compare the aforementioned glass to 25 , which crystallized $29 \%$ nepheline. Recall that both these glasses have very similar positions on the $\mathrm{Na}_{2} \mathrm{O}-\mathrm{Al}_{2} \mathrm{O}_{3}-\mathrm{SiO}_{2}$ ternary and very similar optical basicities. Glass 25 can be described as 1.00:0.86:1.07 Si:Al:B and 1.00:0.86:0.25 Si(IV):Al(IV):B(IV) before crystallization. After CCC, the residual glass is 1:00:0.76:1.76 Si:Al:B and 1.00:0.76:0.46 Si(IV):Al(IV):B(IV). The main difference with the non-nepheline forming version (24) is that it has smaller $\mathrm{Na} / \mathrm{Si}$ and $\mathrm{B} / \mathrm{Si}$ in the starting glass. Conventional wisdom $[8,10]$ suggests that having higher $\mathrm{B}_{2} \mathrm{O}_{3}$ concentrations suppresses nepheline formation, but it is clear in this instance that is not the case. Note that the $\mathrm{B}_{2} \mathrm{O}_{3}$ concentrations in these glasses is relatively high, $18-20$ wt $\% \mathrm{~B}_{2} \mathrm{O}_{3}$, which normally would prevent nepheline formation except in the region in question on the $\mathrm{Na}_{2} \mathrm{O}-\mathrm{Al}_{2} \mathrm{O}_{3}-\mathrm{SiO}_{2}$ ternary [10]. In fact, the only compositional difference between these two glasses is $1 \mathrm{wt} \%$ ( 1 mol\%) more $\mathrm{SiO}_{2}$ and $1 \mathrm{wt} \%$ ( 1 mol\%) less $\mathrm{B}_{2} \mathrm{O}_{3}$ in the glass not forming nepheline (24) than in the glass forming nepheline (25). The question then arises as to the significance of the increase in $\mathrm{B}(\mathrm{IV})$ for the glass precipitating nepheline and why $B(I V)$ decreases when nepheline is not formed.

Comparison of the molar ratios of glass formers shows that glass 4 is the only glass with $\mathrm{Si}$ dominating the tetrahedral network (i.e., $>50 \%$ of the tetrahedral sites), even after crystallization of nepheline. All other glasses have more AI(IV) and B(IV)) than Si before and after crystallization. After CCC, 24 (no nepheline precipitation) has a tetrahedral glass network which is closer to Si dominated, 
whereas 13 becomes much more dominated by $\mathrm{Al}(\mathrm{IV})$ and $\mathrm{B}(\mathrm{IV})$ relative to the $\mathrm{Q}$ glass. Note that this analysis does not consider any Fe or $\mathrm{B}$ (III) which might be in the network. However, the Fe(IV) concentration is small here, and there is good evidence that at least a large fraction of $B(I I I)$ is present as metaborate separated from the main glass network. It may not be totally correct to call the network "phase separated" as plotting the normalized glass compositions onto the $\mathrm{Na}_{2} \mathrm{O}-\mathrm{B}_{2} \mathrm{O}_{3}-\mathrm{SiO}_{2}$ submixture ternary does not put the composition in the traditional borosilicate phase separation region.

\subsection{Distinguishing nepheline formation and adding to the model understanding}

The systematics of when nepheline forms in the high alumina glasses studied here are challenging to discern. Amongst the spectral uncertainties is that borate bands did not occur uniformly in the Raman spectra from these glasses, and there were few bands from $\mathrm{SiO}_{2}$ or $\mathrm{Al}_{2} \mathrm{O}_{3}$ moieties. The 24, 25, 26 glasses are nearly identical compositionally (Table 1 ) yet nepheline crystallized upon heat treatment in 25 and 26 but not in 24. Comparing CCC heat treated 13 to 25 and 26, which all contain nepheline, shows much lower $\mathrm{B}_{2} \mathrm{O}_{3}(5 \%)$ and much higher $\mathrm{CaO}(5 \%)$ in 13 relative to 24,25 , and 26 . Singularly, the higher $\mathrm{CaO}$ concentrations in 13 appears to distinguish the amount of nepheline precipitated in 13-CCC relative to 24-CCC, 25-CCC and 26-CCC. Some nepheline bands observed in exemplar spectra were missing from this and other spectra.

It is worth briefly reconsidering the original aim of this study, that of distinguishing between nepheline-forming and non-nepheline forming compositions. In order to do this, several glasses of similar composition were chosen, with one (24) lacking nepheline formation in the current study. The major findings in investigation of this sample were that 1) it had stronger intensity in the $\sim 500 \mathrm{~cm}^{-1}$ and $\sim 1000 \mathrm{~cm}^{-1}$ Raman regions in the quenched glass and 2) the fraction of $\mathrm{B}(\mathrm{IV}$ ) (N4) decreased after CCC heat treatment in contrast to all the other glasses. The $\sim 1000 \mathrm{~cm}^{-1}$ band is almost surely T-O-Si stretching vibrations and the $\sim 500 \mathrm{~cm}^{-1}$ band is very likely Al-O-Si bending in 6-membered "nephelinelike" rings. The fact that these are strongest in the sample which did not precipitate nepheline suggests that perhaps there are a large number of these Na-Al-Si-O moieties but that they are not congregated or clustered in a way that facilitates crystallization. A similar situation, though very different chemistry, may exist in spinel crystallization in nuclear waste glasses, where certain chemical additives create a larger number density of spinel crystals but of a much smaller average size [102]. It may be that the borate network separates these nanocrystals [9] in such a way that they do not coalesce or grow. Before embarking on such speculation, it is worth considering that kinetic factors may be dominant as well. For example, the original report of glass 24 fabrication and heat treatment indicated 2-3 vol\% (determined by optical and scanning electron microscope) of "spinel and nepheline" crystals [66], whereas the current study based on XRD did not find any nepheline. Similarly, glass 25 was originally reported as 1.5 2 vol\% "spinel and nepheline" [66], whereas this same composition produce $29 \%$ nepheline by XRD in the current study. More important, then, is the question of what may be the glass structure similarities leading to potential for nepheline crystallization in all these glasses.

To consider what glass structure might be favorable to nepheline formation one should go back and consider the theoretical assumptions about the structure of glass in general [103, 104]. One extreme model of glass is that it is a continuous random network or frozen liquid, mostly well-known from Zacharaisen [105]. The diametrically opposing view, established earlier, was that of Lebedev [106] who thought glass was composed of "microcrystallites" of $0.8-2 \mathrm{~nm}$ in size (a few atomic spacings) with amorphous matrix. Later refinement of this model prompted Lebedev to rename these regions 
"microheterogeneity," focusing rather on the difference between chemically and structurally ordered versus disordered regions [103]. It is now apparent from better characterization techniques and exploration of more glass-forming systems that this dichotomy is rather a continuous change, where certain systems favor one versus the other extreme with many gradations between [104, 107]. Nuclear waste glasses, then, being very chemically complicated materials, might be expected to be midway along this continuum. Though long-range order is absent in most quenched glasses, short and mediumrange order is clear when borate species unmix and "phase separate" so that they are locally chemically ordered. Crystallization (such as with nepheline) can be seen as a special case of unmixing, where the phase separation is between a crystalline phase and a residual glass phase. Thus the local bond coordinations in the quenched glass and their changes with heat treatment should be considered carefully. In some cases nanocrystalline seeds of nepheline can be clearly identified in transmission electron microscopy when they are not evident in XRD [9]. In other cases the propensity for nepheline formation should be understood as "embryos" or local moieties of structure similar to nepheline crystals. For example, melts of $\mathrm{Na}-\mathrm{Al}-\mathrm{Si}-\mathrm{O}$ are known to consist of 6-membered rings even if their stoichiometry in crystalline form are 4-membered feldspars or chain silicates [59]. Local chemical ordering of Si-Al-Si tetrahedra in 6-membered rings with nearby compensating $\mathrm{Na}$, therefore constitutes a medium-range order with topology identical to a nepheline layer. All that remains is to provide a nucleation site such that the crystal of nominally identical composition to the local glass will form. The extent of crystallization and the structure of the residual glass will be determined by the normalized distribution of tetrahedral sites, their connectivity, the remaining non-tetrahedral glass-formers (e.g., boron, phosphorus, etc.), and the distribution of compensation cations (alkali and sometimes alkalineearth) and network modifiers resulting in non-bridging oxygens. In the case of the glasses in this paper, the resultant glass structure is likely to be one of $\mathrm{Na}-\mathrm{Al}-\mathrm{Si}-\mathrm{O}$ moieties with some $\mathrm{B}(\mathrm{IV})$ intermixed and a nominally separate network of $\mathrm{B}(\mathrm{III})$ species consisting of metaborate chains or rings.

It is prudent now to revisit the original model of this work, the nepheline discriminator (and its extension the position on the normalized submixture ternary $\mathrm{Na}_{2} \mathrm{O}-\mathrm{Al}_{2} \mathrm{O}_{3}-\mathrm{SiO}_{2}$ ) and optical basicity. The glasses in the series considered here generally failed the ND-OB model in that they were below the threshold basicity line yet formed nepheline. In calculating the basicity a single OB value was used for each of boron and silicon. In the original conception and formulation of theoretical OB, Duffy and Ingram [108] posited "microbasicity" which depended on local structure involving coordination and number of non-bridging oxygens. Experimental measurements including $x$-ray photoelectron spectroscopy [109] and NMR, particularly ${ }^{29} \mathrm{Si}$ [110] and ${ }^{11} \mathrm{~B}$ [111] chemical shift, have been shown to relate $\mathrm{OB}$ to electron density and the paramagnetic component of chemical shift. It is possible that with detailed chemical ordering information as obtainable by spectroscopic information, a more refined computation of basicity would flag these glasses as potentially problematic for nepheline crystallization. However, this is impractical from the standpoint of predicting a priori the propensity for nepheline formation based on composition. While this study did not clearly establish a discriminator for nepheline formation from compositional considerations, it did reveal that local inhomogeneities, particularly in the lack of connectivity between the B(III) (metaborate) structures and the sodium aluminosilicate structures as evidenced by Raman spectroscopy, may result in a situation where crystalline nepheline has lower energy than the equivalent glassy sodium aluminosilicate structure. Given the large amount of $\mathrm{B}_{2} \mathrm{O}_{3}$ in these glasses, and general perception that boron inhibits nepheline formation, this study has 
shown that the reality is more complicated and depends largely on the valence of $B$, and the connectivity of $\mathrm{B}(\mathrm{III})$.

\section{Summary and Conclusions}

In this paper the structure of feldspathoid nepheline-like crystals and their glass analogues are reviewed with the goal of understanding melt structure precursors to crystal formation in alumino-borosilicate nuclear waste glasses. Six glass compositions were selected from a large dataset and compared to nepheline mineral and pure sodium nepheline glass. A spectroscopic study using multi-nuclear NMR, Raman spectroscopy, and Mössbauer was conducted to explore the role of glass-forming elements $\mathrm{Si}, \mathrm{Al}$, $\mathrm{B}$, along with $\mathrm{Na}$ and $\mathrm{Fe}$, and to understand their connectivity.

NMR showed the appearance of two sites for $\mathrm{Al}, \mathrm{Si}$, and $\mathrm{Na}$ in the samples which crystallized significant amounts of nepheline, and $B$ speciation changed, typically resulting in more $B(I V)$ after nepheline crystallization. Raman spectroscopy suggested a major part of the glass structure is composed of metaborate chains or rings, suggesting significant numbers of non-bridging oxygens (NBO) and a separation of the borate from the alumino-silicate network. Mössbauer combined with Fe redox chemical measurements showed that Fe plays a minor role in these glasses, mostly as $\mathrm{Fe}^{3+}$, but that iron oxide spinel forms with nepheline in all cases.

Using experimental B(IV) fraction obtained by NMR, the Darab et al. [21] model, which computes partitioning of alkali, predicted a large amount of NBO consistent with Raman spectra of metaborates. An alternative notion for appreciating the glass network is suggested where network formers are normalized on a molar basis to $\mathrm{Si}$, then NMR data allows correction for tetrahedral coordination. This notion is then used to investigate the changes in the glass due to crystallization of sodium nepheline and the resulting residual glass network and composition. The role of boron at high concentrations in nuclear waste glass may not be strictly advantageous to prevent nepheline crystallization if it results in large concentrations of NBO and network unmixing, leaving Na-Al-Si regions unconnected to the borate network.

From a theoretical standpoint, it may be preferred to picture nuclear waste glasses by the Lebedev theory of glass structure where "microcrystallites" of ordered nuclei (or embryos) exist in the matrix of more disordered glass. Then, crystallization can be considered as unmixing and coalescence of portions of the "multiphase" melt, possibly in the presence of a nucleating crystal of a different chemistry (in this case spinel). In the future, more glasses of this level of complexity and boron content should be investigated similarly, particularly with Raman spectroscopy, to further corroborate the role of the borate network in crystallization. Additionally, the here-to-fore unexplored role of Li and the significance of the mixed alkali effect in nepheline crystallization should be considered.

\section{Acknowledgements}

This work was supported by the Department of Energy (DOE)'s Waste Treatment \& Immobilization Plant Federal Project Office under the direction of Dr. Albert A. Kruger at DOE. A portion of the research was performed at Pacific Northwest National Laboratory (PNNL), operated by Battelle Memorial Institute for the U.S. DOE under contract DE-AC05-76RL01830. A portion of this research was performed using the 
Environmental Molecular Sciences Laboratory (EMSL), a national scientific user facility sponsored by the DOE's Office of Biological and Environmental Research and located at PNNL.

The authors thank Jarrod Crum for comments on the manuscript, Marc Bowden and Owen Neill for assistance with XRD, Ben Stevens for assistance with fabrication of some of the glasses, Mike Schweiger John Vienna, and Pavel Hrma for helpful discussions, and Josh Boerstler and David Peeler for inspiration and testing of the optical basicity concept. 


\section{References}

[1] P. J. Certa and P. A. Empey, River Protection Project System Plan, Office of River Protection, US Department of Energy, ORP-11242 Revision 6 (2011).

[2] I. Joseph, B. W. Bowan II, H. Gan, W. Kot, K. S. Matlack, I. L. Pegg and A. A. Kruger, High aluminum HLW glasses for Hanford's WTP, Waste Management 2010 (WM-2010), Phoenix, AZ (2010).

[3] J. Amoroso, Computer modeling of high-level waste glass temperatures within DWPF canisters during pouring and cool down, Savannah River National Laboratory, SRNL-STI-2011-00546 (2011).

[4] J. Amoroso, The impact of kinetics on nepheline formation in nuclear waste glasses, Savannah River National Laboratory, SRNL-STI-2011-00051 (2011).

[5] J. D. Vienna, Int. J. Appl. Glass Sci. 1 (3) (2010) 309-321.

[6] P. Hrma, M. J. Schweiger, C. J. Humrickhouse, J. A. Moody, R. M. Tate, T. T. Rainsdon, N. E. TeGrotenhuis, B. M. Arrigoni, J. Marcial, C. P. Rodriguez and B. H. Tincher, Ceramics-Silikaty 54 (2010) 193-211.

[7] P. Hrma, J. Non-Cryst. Solids 356 (2010) 3019-3025.

[8] K. M. Fox, T. B. Edwards and D. K. Peeler, Int. J. Appl. Ceram. Technol. 5 (6) (2008) 666-673.

[9] H. Li, P. Hrma, J. D. Vienna, M. Qian, Y. Su and D. E. Smith, J. Non-Cryst. Solids 331 (1-3) (2003) 202-216.

[10] J. S. McCloy, M. J. Schweiger, C. P. Rodriguez and J. D. Vienna, Int. J. Appl. Glass Sci. 2 (3) (2011) 201-214.

[11] K. M. Fox, J. D. Newell, T. B. Edwards, D. R. Best, I. A. Reamer and R. J. Workman, Refinement of the nepheline discriminator: results of a Phase I Study, Savannah River National Laboratory, WSRC-STI-2007-00659 (2007).

[12] L.-S. Du and J. F. Stebbins, J. Non-Cryst. Solids 351 (43-45) (2005) 3508-3520.

[13] J. Wu and J. F. Stebbins, J. Non-Cryst. Solids 355 (2009) 556-562.

[14] Q. Zheng, M. Potuzak, J. C. Mauro, M. M. Smedskjaer, R. E. Youngman and Y. Yue, J. Non-Cryst. Solids 358 (6-7) (2012) 993-1002.

[15] Z.-x. Hou, S.-h. Wang, Z.-I. Xue, H.-r. Lu, C.-I. Niu, H. Wang, B. Sun and C. Su, J. Non-Cryst. Solids 356 (4-5) (2010) 201-207.

[16] V. Swamy, I.-H. Jung and S. A. Decterov, J. Non-Cryst. Solids 355 (34-36) (2009) 1679-1686.

[17] T. M. Besmann and K. E. Spear, J. Amer. Ceram. Soc. 85 (12) (2002) 2887-2894.

[18] G. Lambotte and P. Chartrand, J. Chem. Thermodyn. 57 (0) (2013) 306-334.

[19] B. C. Bunker, R. J. Kirkpatrick, R. K. Brow, G. L. Turner and C. Nelson, J. Amer. Ceram. Soc. 74 (6) (1991) 1430-1438.

[20] W. J. Dell, P. J. Bray and S. Z. Xiao, J. Non-Cryst. Solids 58 (1) (1983) 1-16.

[21] J. G. Darab, X. Feng, J. C. Linehan, P. A. Smith and I. Roth Composition-stucture relationships in model Handford low-level waste glasses. In: V. Jain and D. K. Peeler, Editors, Ceramic Transactions, American Ceramic Society, Westerville, OH (1996).

[22] I. Dvorinchenko and S. Matsenko, Glass and Ceramics 57 (1) (2000) 11-13.

[23] L. Cormier, D. Ghaleb, J. M. Delaye and G. Calas, Phys. Rev. B 61 (21) (2000) 14495-14499.

[24] J. C. C. Chan, M. Bertmer and H. Eckert, J. Am. Chem. Soc. 121 (22) (1999) 5238-5248.

[25] R. K. Brow, D. R. Tallant and G. L. Turner, J. Amer. Ceram. Soc. 80 (5) (1997) 1239-1244.

[26] E. M. Pierce, L. R. Reed, W. J. Shaw, B. P. McGrail, J. P. Icenhower, C. F. Windisch, E. A. Cordova and J. Broady, Geochim. Cosmochim. Act. 74 (9) (2010) 2634-2654. 
[27] B. Cochain, D. R. Neuville, G. S. Henderson, C. A. McCammon, O. Pinet and P. Richet, J. Am. Ceram. Soc. 95 (3) (2012) 962-971.

[28] P. A. Bingham, J. M. Parker, T. Searle, J. M. Williams and I. Smith, C. R. Chimie 5 (2002) 787-796.

[29] P. A. Bingham, O. M. Hannant, N. Reeves-McLaren, M. C. Stennett and R. J. Hand, J. Non-Cryst. Solids 387 (0) (2014) 47-56.

[30] S. Musić, K. Furić, Z. Bajs and V. Mohaček, J. Mater. Sci. 27 (19) (1992) 5269-5275.

[31] R. K. Kukkadapu, H. Li, G. L. Smith, J. D. Crum, J.-S. Jeoung, W. Howard Poisl and M. C. Weinberg, J. Non-Cryst. Solids 317 (3) (2003) 301-318.

[32] S. V. Stefanovsky, B. S. Nikonov and J. C. Marra, Glass Phys. Chem. 34 (3) (2008) 292-299.

[33] C. M. Jantzen and K. G. Brown, J. Amer. Ceram. Soc. 90 (6) (2007) 1866-1879.

[34] P. Hrma, B. J. Riley, J. V. Crum and J. Matyas, J. Non-Cryst. Solids 384 (0) (2014) 32-40.

[35] A. L. Billings, C. M. Jantzen, C. C. Herman and S. L. Marra, Phase Stability of Defense Waste Processing Facility (DWPF) Type High Level Nuclear Waste Glasses, John Wiley \& Sons, Inc., (2010).

[36] S. V. Stefanovsky, K. M. Fox, J. C. Marra, A. A. Shiryaev and Y. V. Zubavichus, Phys. Chem. Glasses 53 (4) (2012) 158-166.

[37] D. C. Palmer Stuffed derivatives of the silica polymorphs. In: P. J. Heaney, C. T. Prewitt and G. V. Gibbs, Editors, Silica: Physical behavior, geochemistry and materials applications, Mineralogical Society of America, Washington D. C. (1994).

[38] H. A. Graetsch and W. Schreyer, Can. Mineral. 43 (2) (2005) 759-767.

[39] W. A. Dollase and W. M. Thomas, Contrib. Mineral. Petr. 66 (3) (1978) 311-318.

[40] K. T. Tait, E. Sokolova and F. C. Hawthorne, Can. Mineral. 41 (2003) 61-70.

[41] T. Hahn and M. J. Buerger, Z. Kristallogr. 106 (1-6) (1954) 308-338.

[42] G. L. Hovis, D. R. Spearing, J. F. Stebbins, J. Roux and A. Clare, Amer. Mineral. 77 (1992) 19-29.

[43] S. M. Antao and I. Hassan, Can. Mineral. 48 (1) (2010) 69-80.

[44] J. F. Stebbins, J. B. Murdoch, I. S. E. Carmichael and A. Pines, Phys. Chem. Miner. 13 (6) (1986) 371-381.

[45] P. Vulić, T. Balić-Žunić, L. Belmonte and V. Kahlenberg, Miner. Petrol. 101 (3-4) (2011) 185-194.

[46] G. Rossi, R. Oberti and D. C. Smith, Eur. J. Mineral. 1 (1) (1989) 59-70.

[47] M. J. Buerger, G. E. Klein and G. Donnay, Am. Mineral. 39 (1954) 805-818.

[48] W. A. Deer, R. A. Howie and J. Zussman Nepheline Group. An Introduction to Rock-Forming Minerals, Addison-Wesley Longman, London (1992).

[49] W. A. Deer, R. A. Howie, W. S. Wise and J. Zussman, Editors, Framework Silicates: Silica Minerals, Feldspathoids and the Zeolites, The Geological Society, London (2004).

[50] R. J. Angel, G. D. Gatta, T. B. Ballaran and M. A. Carpenter, Can. Mineral. 46 (6) (2008) 14651476.

[51] K. Friese, A. Grzechnik, V. Petříček, A. Schönleber, S. van Smaalen and W. Morgenroth, Acta Crystallogr. B 67 (1) (2011) 18-29.

[52] G. D. Gatta and R. J. Angel, Am. Mineral. 92 (8-9) (2007) 1446-1455.

[53] B. Hippler and H. Bohm, Z. Kristallogr. 187 (1989) 39-53.

[54] V. Kahlenberg and H. Bohn, Am. Mineral. 83 (5-6) (1998) 631-637.

[55] P. Vulić, V. Kahlenberg and J. Konzett, Am. Mineral. 93 (7) (2008) 1072-1079.

[56] A. Radulovic, V. Dondur, P. Vulic, Z. Miladinovic, G. Ciric-Marjanovic and R. Dimitrijevic, J. Phys. Chem. Solids 74 (9) (2013) 1212-1220.

[57] D. W. Matson, S. K. Sharma and J. A. Philpotts, Amer. Mineral. 71 (5-6) (1986) 694-704.

[58] N. Tsomaia, S. L. Brantley, J. P. Hamilton, C. G. Pantano and K. T. Mueller, Amer. Miner. 88 (1) (2003) 54-67.

[59] M. Taylor and G. E. Brown Jr, Geochim. Cosmochim. Acta 43 (9) (1979) 1467-1473. 
[60] M. Taylor and G. E. Brown Jr, Geochim. Cosmochim. Acta 43 (1) (1979) 61-75.

[61] M. Taylor, G. E. Brown Jr and P. M. Fenn, Geochim. Cosmochim. Acta 44 (1) (1980) 109-117.

[62] K. L. Geisinger, R. Oestrike, A. Navrotsky, G. L. Turner and R. J. Kirkpatrick, Geochim. Cosmochim. Acta 52 (10) (1988) 2405-2414.

[63] M. E. Fleet, Am. Mineral. 77 (1992) 76-84.

[64] D. E. Appleman and J. R. Clark, Am. Mineral. 50 (11-12) (1965) 1827-1850.

[65] E. V. Sokolova, F. C. Hawthorne and A. P. Khomyakov, Can. Mineral. 39 (1) (2001) 159-169.

[66] K. S. Matlack, H. Gan, W. Gong, I. L. Pegg, C. C. Chapman and I. Joseph, High Level Waste Vitrification System Improvements, Vitreous State Laboratory, the Catholic University of America, VSL-07R1010-1 (2007).

[67] D. S. Kim, M. J. Schweiger, C. P. Rodriguez, W. C. Lepry, J. B. Lang, J. D. Crum, J. D. Vienna, F. C. Johnson, J. C. Marra and D. K. Peeler, Formulation and Characterization of Waste Glasses with Varying Processing Temperature, Pacific Northwest National Laboratory, PNNL-20774, EMSPRPT-009 (2011).

[68] C. P. Rodriguez, J. McCloy, M. J. Schweiger, J. V. Crum and A. Winschell, Optical basicity and nepheline crystallization in high alumina glasses, Pacific Northwest National Laboratory, PNNL20184 (2011).

[69] Anon., Memorandum, Canister Centerline Cooling Data, Revision 1, October 29, 2003, CCN: 074851, RPP-WTP (2003).

[70] L. J. Mueller, Chemical Exchange in NMR, California Institute of Technology, PhD (1997).

[71] K. J. Sutovich, A. W. Peters, E. F. Rakiewicz, R. F. Wormsbecher, S. M. Mattingly and K. T. Mueller, J. Catalysis 183 (1) (1999) 155-158.

[72] D. G. Rancourt and J. Y. Ping, Nucl. Inst. and Meth. B 58 (1991) 85-97.

[73] C. W. McVay, Determination of the ferrous-ferric ratio in glass, West Valley Nuclear Services Co, ACM-FE-2201, rev 3 (1989).

[74] D. R. Jones, W. C. Jansheski and D. S. Goldman, Anal. Chem. 53 (6) (1981) 923-924.

[75] W. B. Fortune and M. G. Mellon, Ind. Eng. Chem. Analy. Ed. 10 (2) (1938) 60-64.

[76] D. Manara, A. Grandjean and D. R. Neuville, Amer. Mineral. 94 (2009) 777-784.

[77] R. T. Downs, The RRUFF Project: an integrated study of the chemistry, crystallography, Raman and infrared spectroscopy of minerals, Program and Abstracts of the 19th General Meeting of the International Mineralogical Association in Kobe, Japan (2006).

[78] B. O. Mysen and M. J. Toplis, Amer. Mineral. 92 (2007) 933-946.

[79] L. M. Thompson and J. F. Stebbins, J. Non-Cryst. Solids 358 (15) (2012) 1783-1789.

[80] M. J. Toplis, D. B. Dingwell and T. Lenci, Geochim. Cosmochim. Acta 61 (13) (1997) 2605-2612.

[81] X. Xue and J. F. Stebbins, Phys. Chem. Min. 20 (5) (1993) 297-307.

[82] E. Lippmaa, A. Samoson and M. Magi, J. Am. Chem. Soc. 108 (8) (1986) 1730-1735.

[83] T. Nanba, M. Nishimura and Y. Miura, Geochim. Cosmochim. Acta 68 (24) (2004) 5103-5111.

[84] M. M. Islam, D. Holland, A. P. Howes and C. R. Scales, Phys. Chem. Glasses 51 (3) (2010) 137-145.

[85] L.-S. Du and J. F. Stebbins, J. Phys. Chem. B 107 (37) (2003) 10063-10076.

[86] L.-S. Du and J. F. Stebbins, Chem. Mater. 15 (20) (2003) 3913-3921.

[87] B. G. Parkinson, D. Holland, M. E. Smith, A. P. Howes and C. R. Scales, J. Phys. Cond. Matt. 19 (41) (2007) 415114.

[88] A. G. Roca, J. F. Marco, M. d. P. Morales and C. J. Serna, J. Phys. Chem. B 111 (50) (2007) 1857718584.

[89] G. M. Da Costa, E. De Grave, L. H. Bowen, R. E. Vandenberghe and A. De Bakker, Clays Clay Miner. 42 (5) (1994) 628-633.

[90] D. Masih, S. Frank, L. Joachim, R. Nathalie, S. Biplab, K. Werner and W. Heiko, J. Phys. D 45 (19) (2012) 195001. 
[91] J. D. Vienna, P. Hrma, A. Jiricka, D. E. Smith, T. H. Lorier, I. A. Reamer and R. L. Schulz, Hanford Immobilized LAW Product Acceptance Testing: Tanks Focus Area Results, Pacific Northwest National Laboratory, PNNL-13744 (2001).

[92] W. Loewenstein, Am. Mineral. 39 (1954) 92-96.

[93] S. Wang and J. F. Stebbins, J. Amer. Cer. Soc. 82 (6) (1999) 1519-1528.

[94] J. F. Stebbins, S. K. Lee and J. V. Oglesby, Am. Mineral. 84 (1999) 983-986.

[95] S. K. Lee and J. F. Stebbins, Geochim. Cosmochim. Acta 66 (2) (2002) 303-309.

[96] L.-S. Du and J. F. Stebbins, J. Non-Cryst. Solids 315 (2003) 239-255.

[97] S. Sen, E. L. Gjersing, H. Maekawa, Y. Noda, M. Ando, M. Tansho, T. Shimizu, V. P. Klyuev and B. Z. Pevzner, Phys. Chem. Glasses 50 (4) (2009) 262-266.

[98] K. E. Kelsey, J. R. Allwardt and J. F. Stebbins, J. Non-Cryst. Solids 354 (40-41) (2008) 4644-4653.

[99] D. R. Neuville, L. Cormier and D. Massiot, Geochim. Cosmochim. Acta 68 (24) (2004) 5071-5079.

[100] L. M. Thompson and J. F. Stebbins, Am. Mineral. 96 (5-6) (2011) 841-853.

[101] S. K. Lee and J. F. Stebbins, Geochim. Cosmochim. Acta 73 (4) (2009) 1109-1119.

[102] J. Matyáš, A. R. Huckleberry, C. P. Rodriguez, J. B. Lang, A. T. Owen and A. A. Kruger, HLW Glass Studies: Development of Crystal-Tolerant HLW Glasses, Pacific Northwest National Laboratory, PNNL-21308 (2012).

[103] W. Vogel, Glass Chemistry, Springer-Verlag, Berlin (1992).

[104] Z.-H. Jiang and Q.-Y. Zhang, Prog. Mater. Sci. 61 (0) (2014) 144-215.

[105] W. H. Zachariasen, J. Am. Chem. Soc. 54 (10) (1932) 3841-3851.

[106] A. A. Lebedev, Trudy Cossud Opt Inst 2 (1921) 57.

[107] A. C. Wright, Int. J. Appl. Glass Sci. 5 (1) (2014) 31-56.

[108] J. A. Duffy and M. D. Ingram, J. Non-Cryst. Solids 21 (3) (1976) 373-410.

[109] T. Nanba, Y. Miura and S. Sakida, J. Ceram. Soc. Jap. 113 (1) (2005) 44-50.

[110] H. Maekawa, T. Maekawa, K. Kawamura and T. Yokokawa, J. Non-Cryst. Solids 127 (1) (1991) 5364.

[111] Y. Tanaka, Y. Benino, T. Nanba and Y. Miura, Phys. Chem. Glasses 50 (5) (2009) 289-293.

[112] E. F. Osborn and A. Muan, Phase Equilibrium Diagrams of Oxide Systems, American Ceramic Society and the Edward Orton, Jr., Ceramic Foundation, (1960).

\section{Electronic Annex}

Additional supporting information may be found in the online version of this article at the publisher's website, including Raman spectra with labeled peaks, additional Mössbauer data, assignments for Raman bands, and discussion of additional glass structure models. 
Tables

Table 1: Glass compositions discussed (mass \%) and glass compositions of major components (mol\%), where $\mathrm{M}_{2} \mathrm{O}$ includes oxides of $\mathrm{K}, \mathrm{Li}, \mathrm{Na}$, and $\mathrm{Cs}$ and $\mathrm{MO}$ includes oxides of $\mathrm{Ca}, \mathrm{Mg}, \mathrm{Ba}$, and $\mathrm{Sr}$.

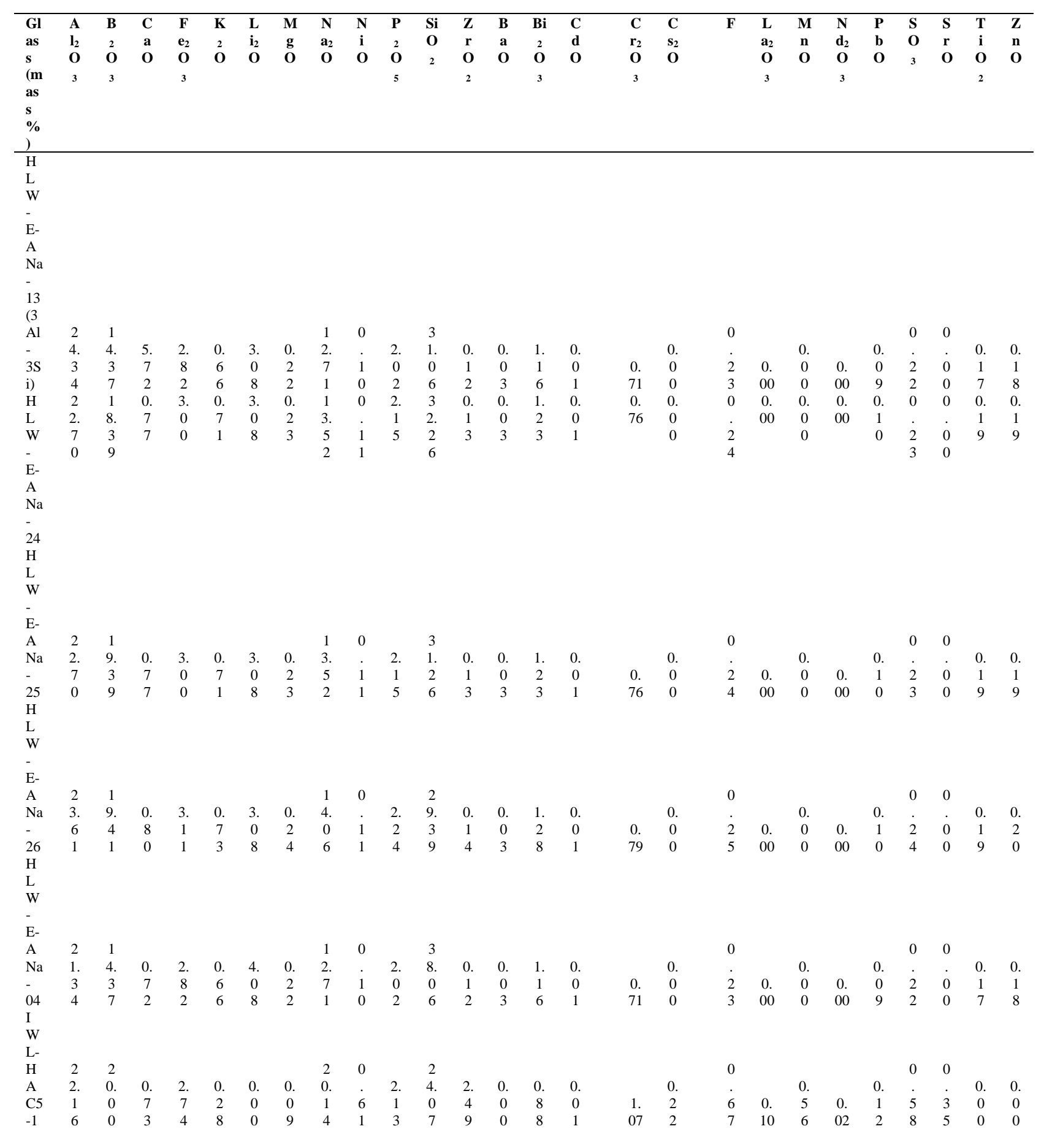

\begin{tabular}{lccccccccc}
\hline Glass (mol \%) & $\mathbf{S i O}_{\mathbf{2}}$ & $\mathbf{A l}_{\mathbf{2}} \mathbf{O}_{\mathbf{3}}$ & $\mathbf{B}_{\mathbf{2}} \mathbf{O}_{\mathbf{3}}$ & $\mathbf{M}_{\mathbf{2}} \mathbf{O}$ & $\mathbf{M O}$ & $\mathbf{F e}_{\mathbf{2}} \mathbf{O}_{\mathbf{3}}$ & $\mathbf{P}_{\mathbf{2}} \mathbf{O}_{\mathbf{5}}$ & $\mathbf{F}$ & others \\
\hline HLW-E-ANa-13(3Al- & & & & & & & & & \\
3Si) & 35.8 & 16.5 & 14.3 & 21.8 & 7.4 & 1.2 & 1.0 & 0.8 & 1.2 \\
HLW-E-ANa-24 & 37.4 & 15.5 & 18.4 & 22.9 & 1.4 & 1.3 & 1.1 & 0.9 & 1.3 \\
HLW-E-ANa-25 & 36.3 & 15.5 & 19.4 & 22.9 & 1.4 & 1.3 & 1.1 & 0.9 & 1.3 \\
HLW-E-ANa-26 & 34.3 & 16.3 & 19.6 & 23.7 & 1.4 & 1.4 & 1.1 & 0.9 & 1.3 \\
HLW-E-ANa-04 & 42.9 & 14.2 & 14.0 & 23.6 & 1.3 & 1.2 & 1.0 & 0.8 & 1.2 \\
IWL-HAC5-1 & 29.2 & 15.8 & 20.9 & 23.9 & 1.4 & 1.2 & 1.1 & 2.6 & 3.9
\end{tabular}


Table 2: Compositional descriptors, crystallinity, and characterization performed. Compositional descriptors include molar ratios, ND, and OB. Crystallinity shown for CCC samples including percent nepheline. Similar ternary and $O B$ is referred to glasses within the cluster number. *Unless otherwise noted, characterization on quenched and CCC samples; \# calculated ratios for theoretical $\mathrm{NaAlSiO}_{4}$ composition. Note that previous studies of XRD of some samples [66], indicated 24 contained 3 vol\% crystals (spinel + sodium aluminosilicate), 25 contained 2 vol\% (spinel + sodium aluminosilicate), and 4 contained $2-5 \mathrm{vol} \%$ crystals (spinel + sodium aluminosilicate), all determined by microscopy methods.

\begin{tabular}{|c|c|c|c|c|c|c|c|c|c|c|c|c|}
\hline Glass & Abbreviation & $\begin{array}{l}\text { Characteriz. } \\
\text { Performed* }\end{array}$ & $\begin{array}{l}\text { CCC } \\
\text { Neph\% } \\
\end{array}$ & $\begin{array}{l}\text { CCC Other } \\
\text { crystals }\end{array}$ & ND & OB & $\mathbf{N a} / \mathbf{S i}$ & $\mathrm{Na} / \mathrm{B}$ & $\mathrm{Na} / \mathbf{A l}$ & $\mathbf{A} \mathbf{l} / \mathbf{S i}$ & $\mathbf{B} / \mathbf{S i}$ & B/Al \\
\hline $\begin{array}{l}\text { HLW-E-ANa- } \\
\text { 13(3Al-3Si) }\end{array}$ & 13 & $\begin{array}{l}\text { XRD,NMR, Raman, } \\
\text { Mossb }\end{array}$ & 38 & $\begin{array}{l}\text { Spinel, } \\
\text { apatite }\end{array}$ & 0.456 & 0.580 & 0.40 & 0.99 & 0.86 & 0.92 & 0.80 & 0.86 \\
\hline HLW-E-ANa-24 & 24 & $\begin{array}{l}\text { XRD,NMR, Raman, } \\
\text { Mossb }\end{array}$ & 0 & Spinel & 0.471 & 0.558 & 0.41 & 0.83 & 0.98 & 0.83 & 0.98 & 1.19 \\
\hline HLW-E-ANa-25 & 25 & XRD,NMR, Raman & 29 & $\alpha \mathrm{Fe}_{2} \mathrm{O}_{3}$ & 0.463 & 0.557 & 0.42 & 0.78 & 0.98 & 0.86 & 1.07 & 1.25 \\
\hline HLW-E-ANa-26 & 26 & $\begin{array}{l}\text { XRD,NMR, Raman, } \\
\text { Mossb }\end{array}$ & 14 & Spinel & 0.438 & 0.561 & 0.46 & 0.81 & 0.98 & 0.95 & 1.14 & 1.20 \\
\hline HLW-E-ANa-04 & 4 & XRD, NMR, Raman & 22 & $\begin{array}{l}\text { Spinel, Li-P- } \\
\text { O }\end{array}$ & 0.528 & 0.562 & 0.32 & 0.99 & 0.98 & 0.66 & 0.65 & 0.99 \\
\hline IWL-HAC5-1 & $5-1$ & $\begin{array}{l}\text { XRD, NMR, Raman, } \\
\text { Mossb }\end{array}$ & 5 & $\begin{array}{l}\text { Spinel, } \\
\text { apatite }\end{array}$ & 0.363 & 0.575 & 0.81 & 1.13 & 1.50 & 1.08 & 1.43 & 1.32 \\
\hline Nepheline mineral\# & & XRD, NMR & N/A & $\begin{array}{l}\text { N/A } \\
\text { N/A }\end{array}$ & 0.423 & 0.608 & 0.50 & N/A & 1.00 & 1.00 & 0.00 & 0.00 \\
\hline
\end{tabular}


Table 3: Measured NMR parameters: $\mathrm{T}_{1}$ from ${ }^{23} \mathrm{Na}$ and $\mathrm{N} 4$ from ${ }^{11} \mathrm{~B} . \mathrm{N} / \mathrm{A}$ indicates not applicable and - indicates not measured

\begin{tabular}{|c|c|c|c|c|c|}
\hline \multirow[t]{2}{*}{ Glass } & \multirow{2}{*}{$\begin{array}{c}{ }^{23} \mathrm{Na} \mathrm{T}_{1} \\
(\mathrm{Q}) \\
-5 \mathrm{ppm}\end{array}$} & \multicolumn{2}{|c|}{$\begin{array}{c}{ }^{23} \mathrm{Na} \mathrm{T}_{1} \\
(\mathrm{CCC})\end{array}$} & \multirow[t]{2}{*}{$\begin{array}{l}\text { N4 } \\
\text { (Q) }\end{array}$} & \multirow[t]{2}{*}{$\begin{array}{c}\mathrm{N4} \\
(\mathrm{CCC})\end{array}$} \\
\hline & & $-5 \mathrm{ppm}$ & -20 ppm & & \\
\hline 13 & 0.0170 & 0.0288 & 0.0774 & 0.19 & 0.47 \\
\hline 24 & - & - & - & 0.28 & 0.23 \\
\hline 25 & 0.0151 & 0.0372 & 0.0476 & 0.23 & 0.26 \\
\hline 26 & 0.0139 & 0.0305 & 0.0661 & 0.24 & 0.29 \\
\hline 4 & - & - & - & 0.34 & 0.36 \\
\hline $5-1$ & - & - & - & 0.19 & 0.24 \\
\hline Nepheline mineral & 0.775 & N/A & N/A & N/A & N/A \\
\hline Nepheline glass & 0.029 & N/A & N/A & N/A & N/A \\
\hline
\end{tabular}

Table 4: Spectro-chemical determination of $\mathrm{Fe}^{2+} / \mathrm{Fe}^{3+}$ ratios in $\mathrm{HLW}$ glasses. All reported values are the average $\mathrm{Fe}$ ion $\mathrm{wt} \%$, and they are reported to two standard deviations from the mean.

\begin{tabular}{ccccc} 
Glass & $\mathbf{F e}^{2+}(\mathbf{w t} \%)$ & $\mathbf{F e}_{\text {total }}(\mathbf{w t} \%)$ & $\mathbf{F e}^{\mathbf{3 +}}(\mathbf{w t} \%)$ & $\mathbf{F e}^{\mathbf{2 +}} / \mathbf{F e} \mathbf{s}^{\mathbf{3 +}}$ \\
\hline 13 & $0.16( \pm 0.04)$ & $2.46( \pm 0.08)$ & $2.30( \pm 0.06)$ & $0.06( \pm 0.02)$ \\
24 & $0.12( \pm 0.04)$ & $2.54( \pm 0.09)$ & $2.42( \pm 0.11)$ & $0.05( \pm 0.01)$ \\
25 & $0.10( \pm 0.03)$ & $2.83( \pm 0.23)$ & $2.73( \pm 0.25)$ & $0.04( \pm 0.01)$ \\
26 & $0.10( \pm 0.05)$ & $2.53( \pm 0.06)$ & $2.43( \pm 0.09)$ & $0.04( \pm 0.02)$ \\
4 & $0.12( \pm 0.04)$ & $2.58( \pm 0.14)$ & $2.46( \pm 0.18)$ & $0.05( \pm 0.02)$ \\
$5-1$ & $0.14( \pm 0.02)$ & $2.48( \pm 0.04)$ & $2.34( \pm 0.04)$ & $0.06( \pm 0.01)$ \\
\hline
\end{tabular}

Table 5: Calculated Mössbauer parameters

\begin{tabular}{|c|c|c|c|c|c|c|c|}
\hline Sample & Phase $^{I}$ & $\chi^{2(2)}$ & $\begin{array}{l}\langle\mathrm{CS}\rangle^{3} \\
\mathbf{m m} / \mathbf{s}\end{array}$ & $\begin{array}{c}<\Delta>\text { or }<\boldsymbol{\varepsilon}>^{4} \\
\mathbf{m m} / \mathbf{s}\end{array}$ & $\begin{array}{l}\langle\mathbf{H}\rangle^{5} \\
\text { Tesla }\end{array}$ & $\begin{array}{c}\mathbf{s d}<\Delta>\text { or }<\mathbf{H}>^{6} \\
\mathbf{m m} / \mathbf{s}\end{array}$ & Phase, $\%^{7 *}$ \\
\hline \multirow[t]{4}{*}{ 26-CCC } & $\mathrm{Fe}(\mathrm{III})$-doublet & 1.6 & 0.28 & 0.78 & ${ }_{-}^{\text {na }}$ & 0.38 & $11.16(0.79)$ \\
\hline & $\mathrm{Fe}(\mathrm{III})$-sextet 1 & & 0.32 & -0.004 & 50 & 1.00 & $28.3(1.1)$ \\
\hline & $\mathrm{Fe}(\mathrm{III})$-sextet 2 & & 0.24 & -0.002 & 47.45 & 1.05 & $13.9(1.1)$ \\
\hline & Broad sextet & & 0.07 & -0.225 & 27.8 & 18.7 & $46.6(1.4)$ \\
\hline \multirow[t]{2}{*}{$26-\mathrm{Q}$} & $\mathrm{Fe}$ (III)-doublet & 0.96 & 0.28 & 0.98 & - & 0.56 & $57.4(2.0)$ \\
\hline & Broad sextet & & 0.33 & 0 & 23.3 & 13.7 & $42.6(2.0)$ \\
\hline
\end{tabular}

${ }^{1}$ Spectral component; ${ }^{2}$ reduced chi square; ${ }^{3}$ average center shift; ${ }^{4}$ average quadrupole or average quadrupole shift parameter; ${ }^{5}$ average magnetic hyperfine; ${ }^{6}$ standard deviation of quadrupole shift or magnetic field, ${ }^{7}$ percent contribution with parentheses indicating standard deviation in the fitted fraction, na $=$ not applicable

$*=$ the combined spectral areas of sextet 1 and sextet 2 and that of Fe(III) doublet and broad sextet are rigid. However, the relative areas of sextet 1 and sextet 2 and that of Fe(III) doublet and broad sextet is dependent on standard deviation of these peaks. Lorentzian half widths at half maximum (HWHM) of all elemental Lorentzians in all elemental doublet and sextets were $0.097 \mathrm{~mm} / \mathrm{sec}$ 
Table 6: Computed values for Darab et al [21] model assuming all alkali $\mathrm{M}_{2} \mathrm{O}$ act as $\mathrm{Na}_{2} \mathrm{O}$ and $\mathrm{f}_{\mathrm{B} 4}$ from $\mathrm{NMR}$ data. Also shown are computed compositional ratios of $\mathrm{Na}$ and alkali to quenched glass $\mathrm{B}(\mathrm{IV})$ (i.e., N4) and to non-silica tetrahedra (Al(IV)+B(IV)).

\begin{tabular}{lccccccccc}
$\mathbf{G l a s s}$ & $\begin{array}{c}\mathbf{N a} / \\
\mathbf{B}(\mathbf{I V})\end{array}$ & $\begin{array}{c}\mathbf{N a} / \\
{[\mathbf{A l}(\mathbf{I V})+\mathbf{B}(\mathbf{I V})]}\end{array}$ & $\begin{array}{c}\mathbf{a l k} / \mathbf{A l}(\mathbf{I V})+\mathbf{B}(\mathbf{I V})] \\
\mathbf{f}_{\mathbf{A l k}}\end{array}$ & $\mathbf{f}_{\mathbf{B}}$ & $\mathbf{f}_{\mathbf{B} 4}$ & $\mathbf{f}_{\text {Alk }}^{\text {Al(IV) }}$ & $\mathbf{f}_{\text {Alk }}^{\text {B(IV) }}$ & $\mathbf{f}_{\text {Alk }}^{\text {NBO }}$ \\
\hline 13 & 5.23 & 0.74 & 1.13 & 0.164 & 0.444 & 0.054 & 0.757 & 0.097 & 0.146 \\
24 & 2.95 & 0.74 & 1.11 & 0.199 & 0.496 & 0.102 & 0.677 & 0.144 & 0.179 \\
25 & 3.41 & 0.76 & 1.15 & 0.197 & 0.517 & 0.089 & 0.677 & 0.150 & 0.173 \\
26 & 3.39 & 0.76 & 1.13 & 0.203 & 0.533 & 0.094 & 0.686 & 0.151 & 0.164 \\
4 & 2.92 & 0.73 & 1.25 & 0.266 & 0.395 & 0.095 & 0.600 & 0.142 & 0.258 \\
$5-1$ & 5.95 & 1.19 & 1.21 & 0.228 & 0.589 & 0.079 & 0.661 & 0.180 & 0.159 \\
\hline
\end{tabular}

Table 7: Glass formers and tetrahedral network represented as normalized to a silicon atom. Residual glass after crystallization estimated by subtracting $\mathrm{NaAlSiO}_{4}$ crystallization per the amount shown by XRD (see Section 4.3).

\begin{tabular}{|c|c|c|c|c|c|c|c|c|c|c|c|c|c|c|}
\hline \multirow{3}{*}{$\begin{array}{l}\text { Glass \# } \\
\text { HLW-E-ANa-4 }\end{array}$} & \multicolumn{7}{|c|}{ Starting glass } & \multicolumn{7}{|c|}{ Residual glass after CCC } \\
\hline & \multicolumn{3}{|c|}{ Si:Al:B } & \multirow{2}{*}{$\begin{array}{c}\text { [B(IV)+ } \\
\text { Al(IV)] } \\
\text { /Si(IV) } \\
0.88\end{array}$} & \multicolumn{3}{|c|}{$\mathbf{S i}(I V): A l(I V): B(I V)$} & \multicolumn{3}{|c|}{ Si:Al:B } & \multirow{2}{*}{$\begin{array}{c}\text { B(IV)+ } \\
\text { Al(IV)] } \\
\text { /Si(IV) } \\
0.90\end{array}$} & \multicolumn{3}{|c|}{$\mathbf{S i}(\mathrm{IV}): \mathbf{A l}(\mathbf{I V}): \mathbf{B}(\mathbf{I V})$} \\
\hline & 1.00 & 0.66 & 0.65 & & 1.00 & 0.66 & 0.22 & 1.00 & 0.55 & 0.86 & & 1.00 & 0.55 & 0.31 \\
\hline HLW-E-ANa-13(3Al-3Si) & 1.00 & 0.92 & 0.80 & 1.08 & 1.00 & 0.92 & 0.15 & 1.00 & 0.84 & 1.65 & 1.30 & 1.00 & 0.84 & 0.78 \\
\hline HLW-E-ANa-24 & 1.00 & 0.83 & 0.98 & 1.10 & 1.00 & 0.83 & 0.27 & 1.00 & 0.83 & 0.98 & 1.06 & 1.00 & 0.83 & 0.23 \\
\hline HLW-E-ANa-25 & 1.00 & 0.86 & 1.07 & 1.10 & 1.00 & 0.86 & 0.25 & 1.00 & 0.76 & 1.76 & 1.13 & 1.00 & 0.76 & 0.46 \\
\hline HLW-E-ANa-26 & 1.00 & 0.95 & 1.14 & 1.22 & 1.00 & 0.95 & 0.27 & 1.00 & 0.93 & 1.42 & 1.28 & 1.00 & 0.93 & 0.41 \\
\hline IWL-HAC5-1 & 1.00 & 1.09 & 1.43 & 1.36 & 1.00 & 1.09 & 0.27 & 1.00 & 1.09 & 1.57 & 1.43 & 1.00 & 1.09 & 0.38 \\
\hline
\end{tabular}


Figures

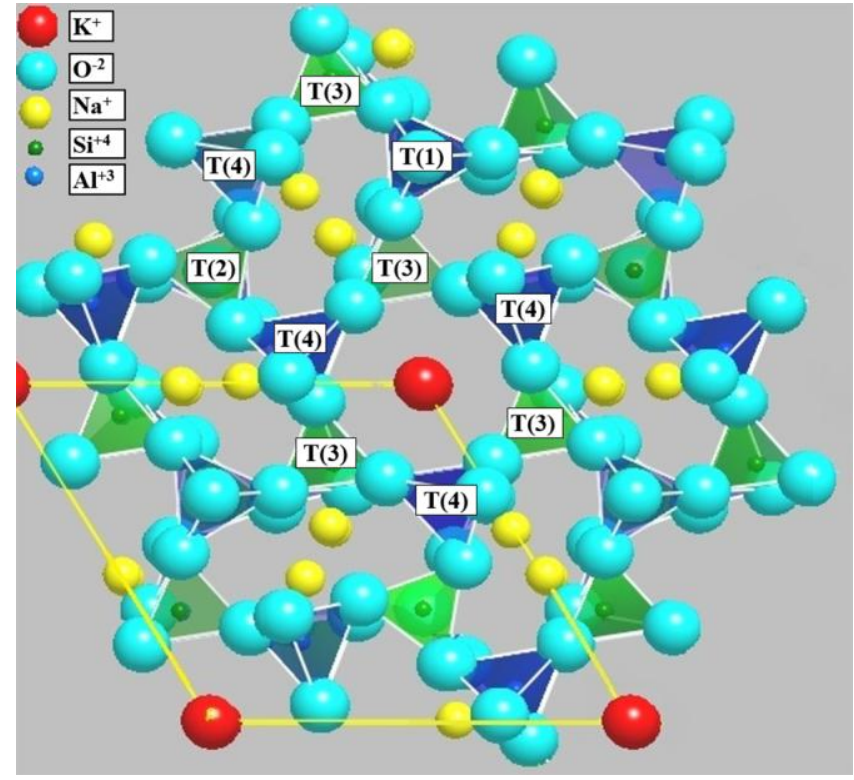

Figure 1 (color online): Structure of hexagonal nepheline according to Hahn and Buerger [41]. View along c-axis of the P6 3 hexagonal nepheline structure showing layer of framework tetrahedra which point alternately up and down and consist of nominally alternating Si and Al atoms. Tetrahedra types $T(1), T(2), T(3)$, and $T(4)$ shown, with the "general" site $T_{G}$ being $T(3)$ and T(4) and the "special" site $T_{S}$ being T(1) and T(2). Redrawn after Deer et al [49] and Tait et al [40]. Hexagonal channels are filled with K atoms or sometimes Na or vacancies. Distorted (ditrigonal) channels are filled with two Na atoms.

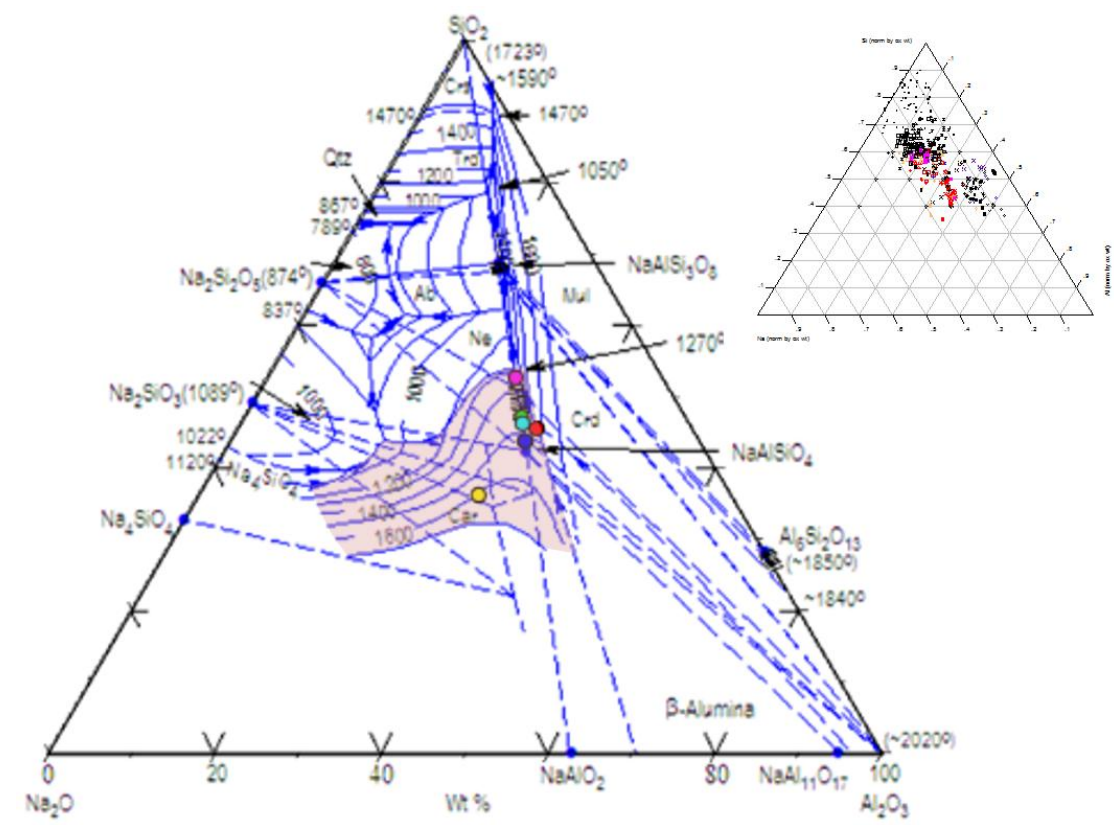

Figure 2 (color online): $\mathrm{Na}_{2} \mathrm{O}-\mathrm{Al}_{2} \mathrm{O}_{3}-\mathrm{SiO}_{2}$ submixture ternary. Carnegieite (Car, $\mathrm{NaAlSiO}_{4}$ phase field shaded) and glasses denoted with circles. Note that most glasses are on the boarder of this region close to the stoichiometric $\mathrm{NaAlSiO}_{4}$ position and the corundum (Crd) primary phase field. Overlay is phase diagram after Osborn and Muan [112]. Inset shows glasses with normalized compositions on this ternary which constitute the database of 629 glass formulations with nepheline formation data. 

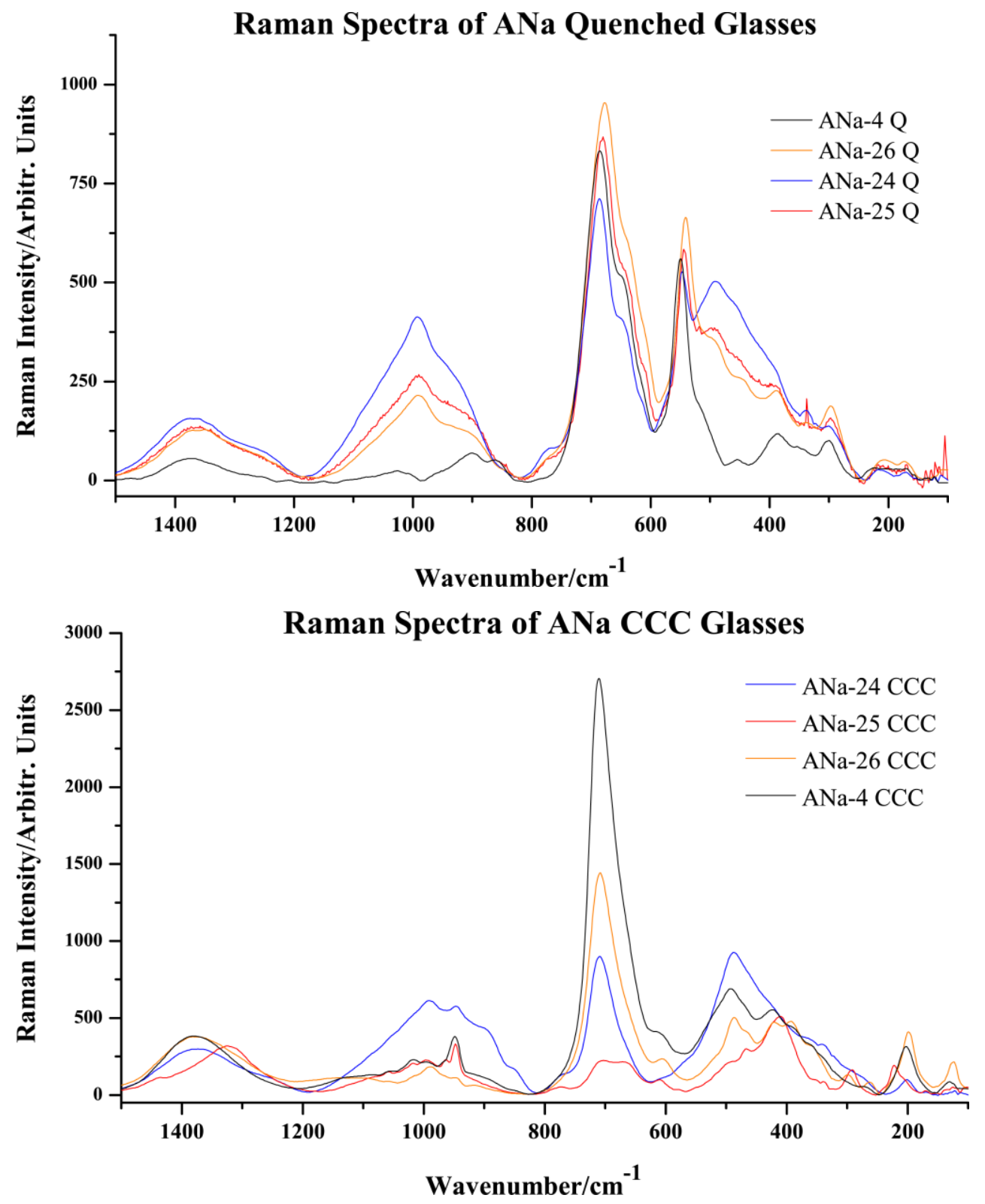

Figure 3: (color online) Raman spectra of (a) quenched glasses and (b) canister centerline cooled (CCC) glasses of: HLW-E-ANa $4,-24,-25,-26$. 


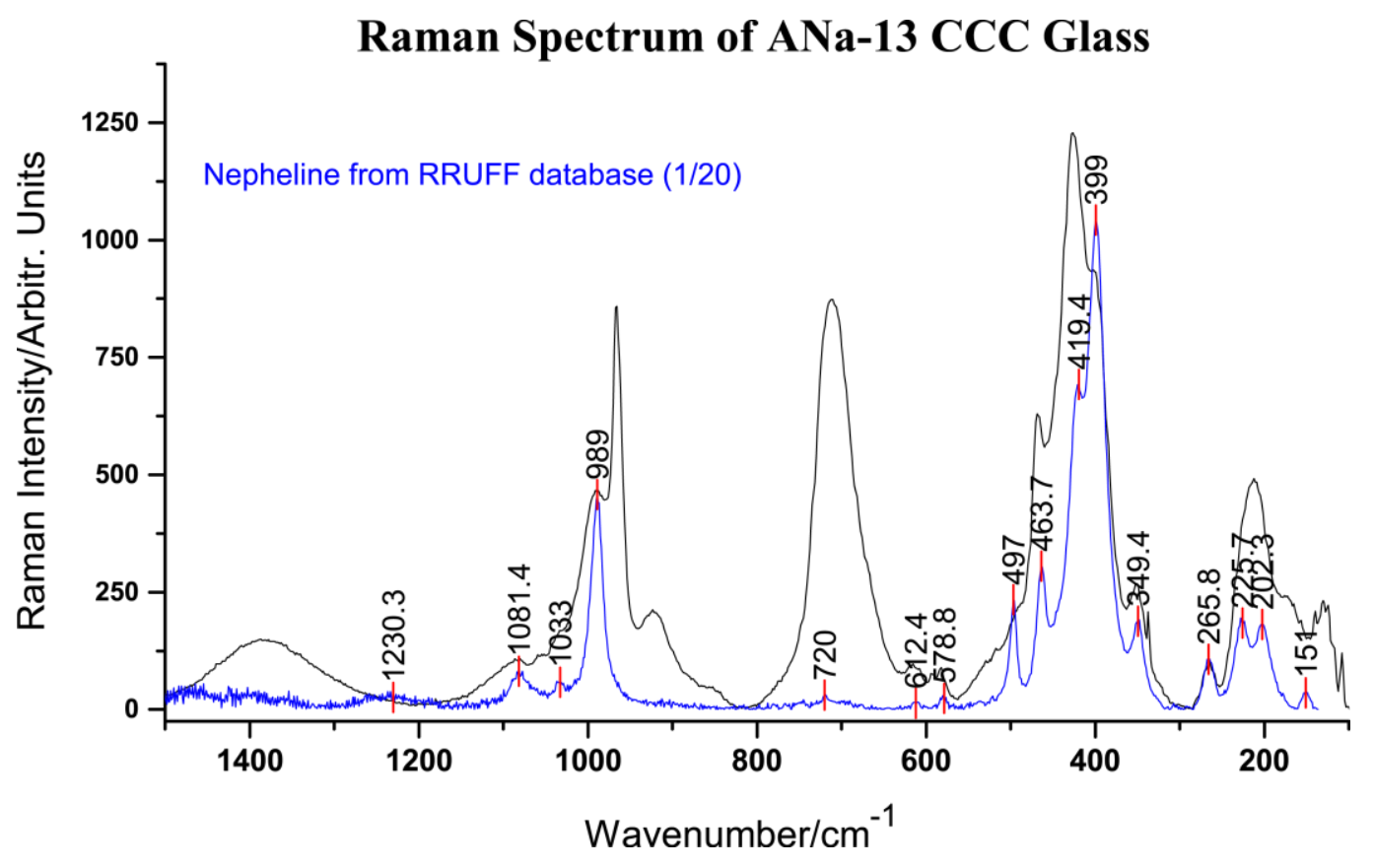

Figure 4: (color online) Raman spectra of canister centerline cooled (CCC) HLW-E-ANa-13(3Al-3Si) ("13") along with nepheline crystal spectrum (Bancroft, RRUF database [77]) 


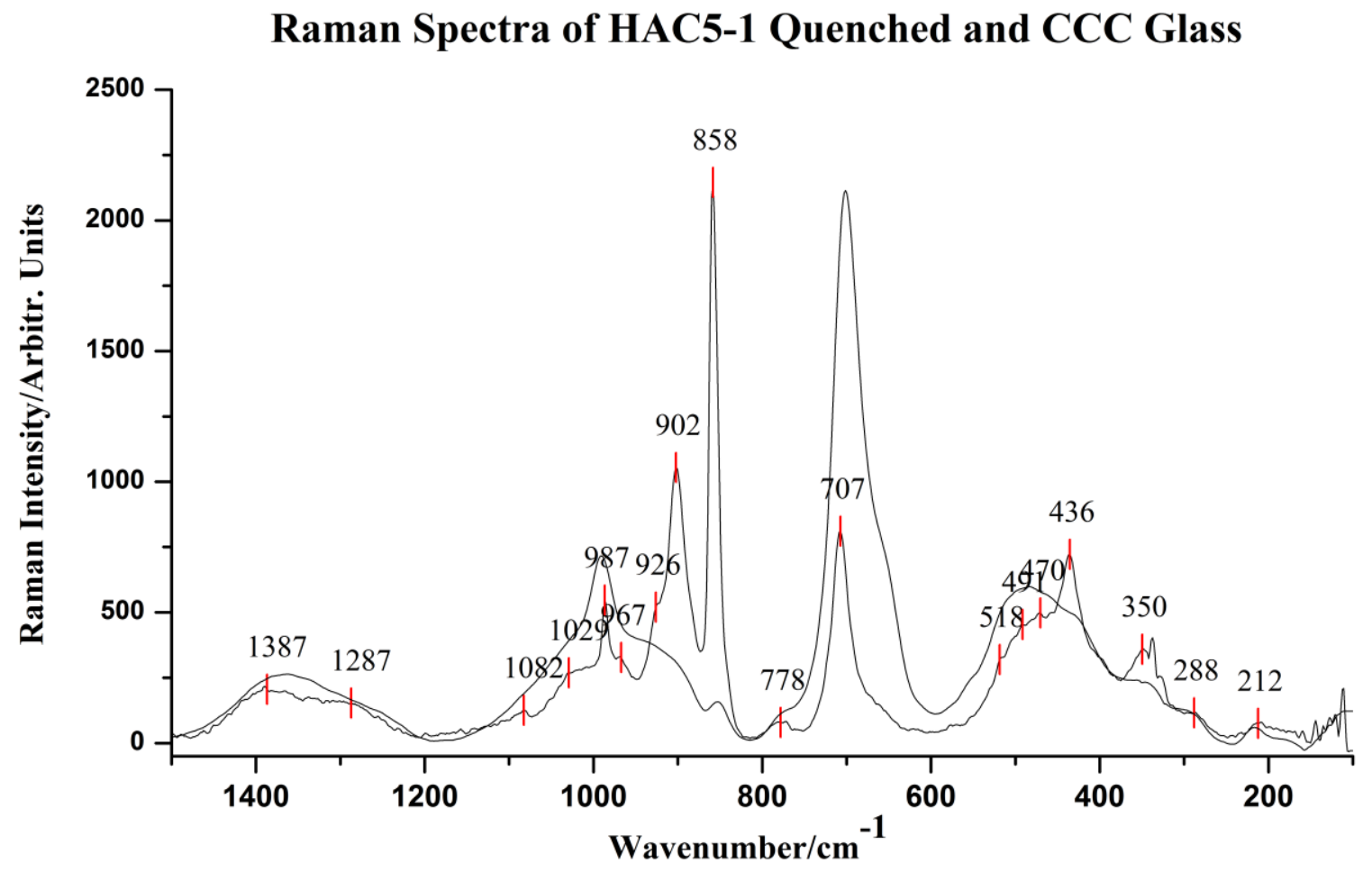

Figure 5: (color online) Raman spectra of quenched and CCC glass IWL-HAC5-1 ("5-1"). The CCC glass spectrum contains the peak at $858 \mathrm{~cm}^{-1}$ 

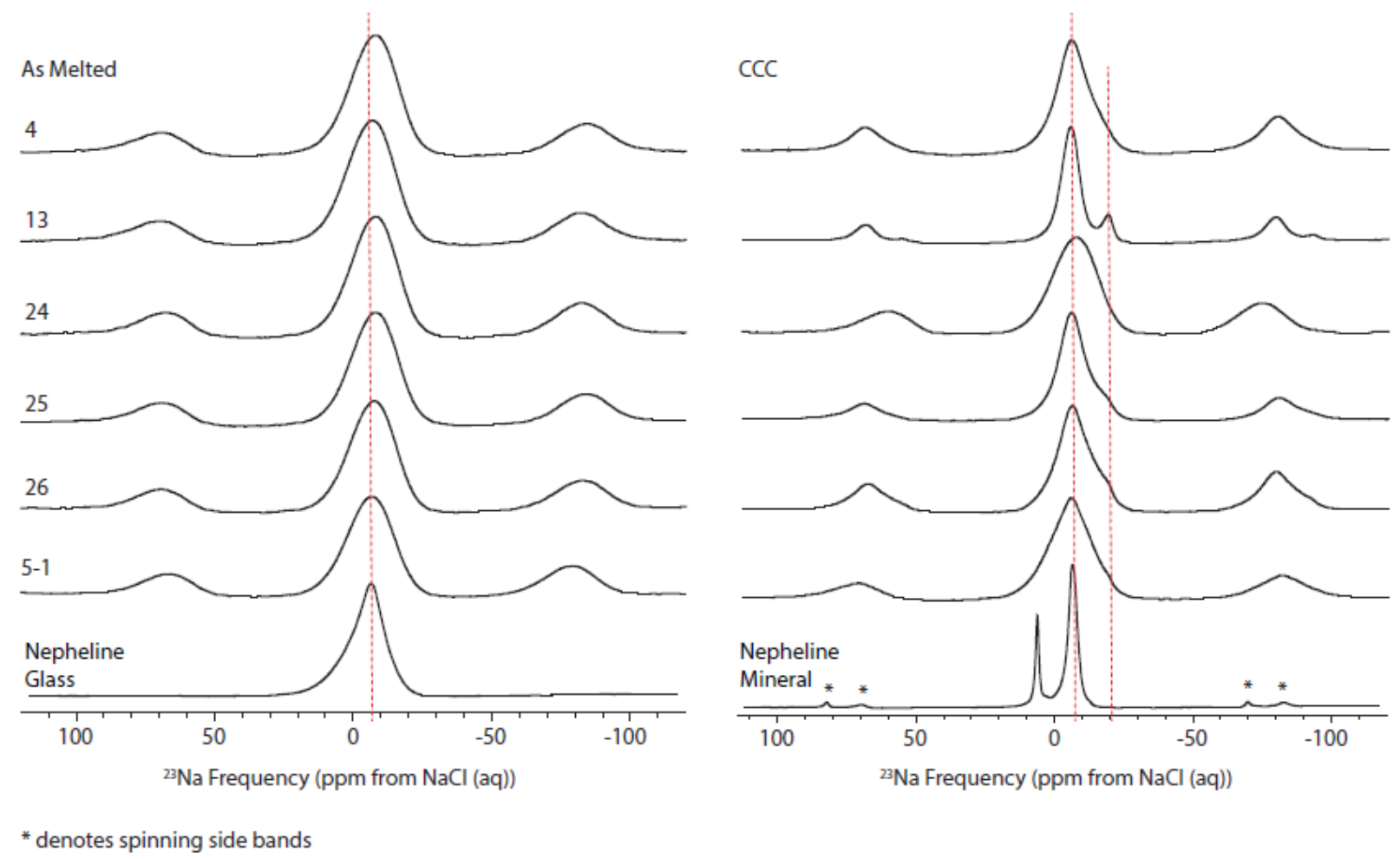

Figure 6: ${ }^{23} \mathrm{Na}(20 \mathrm{~T})$ NMR of quenched (as melted) versus CCC glasses compared to nepheline glass and mineral standards. Lines for comparing across standards are $-5 \mathrm{ppm}$ and $-20 \mathrm{ppm}$. Asterisks (*) denote spinning sidebands. 


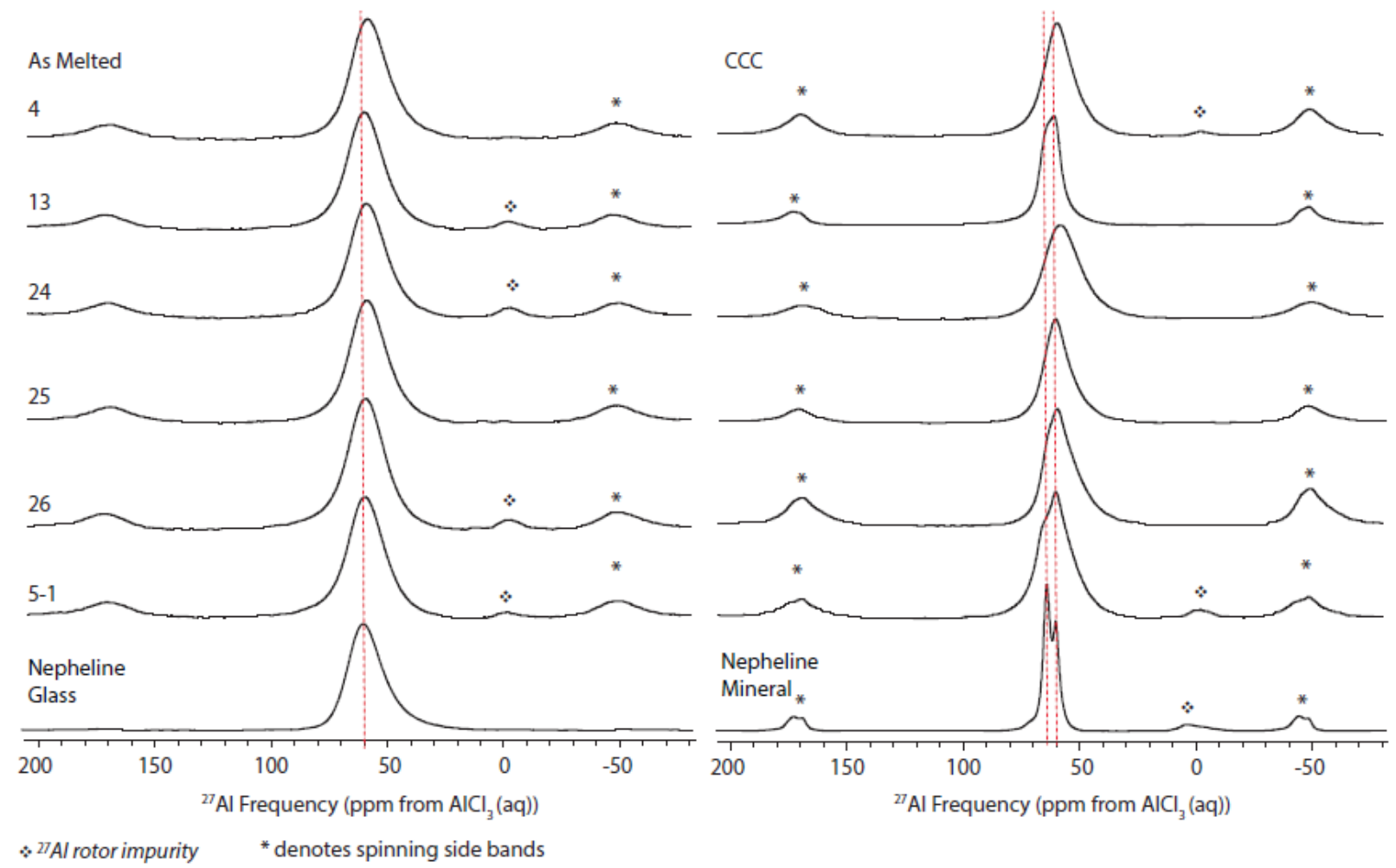

Figure 7: ${ }^{27}$ Al NMR of quenched (as melted) versus CCC glasses compared to nepheline glass and mineral standards. Lines for comparing across standards are 60.5 (both) and 64.5 ppm (CCC only). Asterisks (*) denote spinning sidebands. Diamonds denote $a^{27}$ Al rotor impurity. 

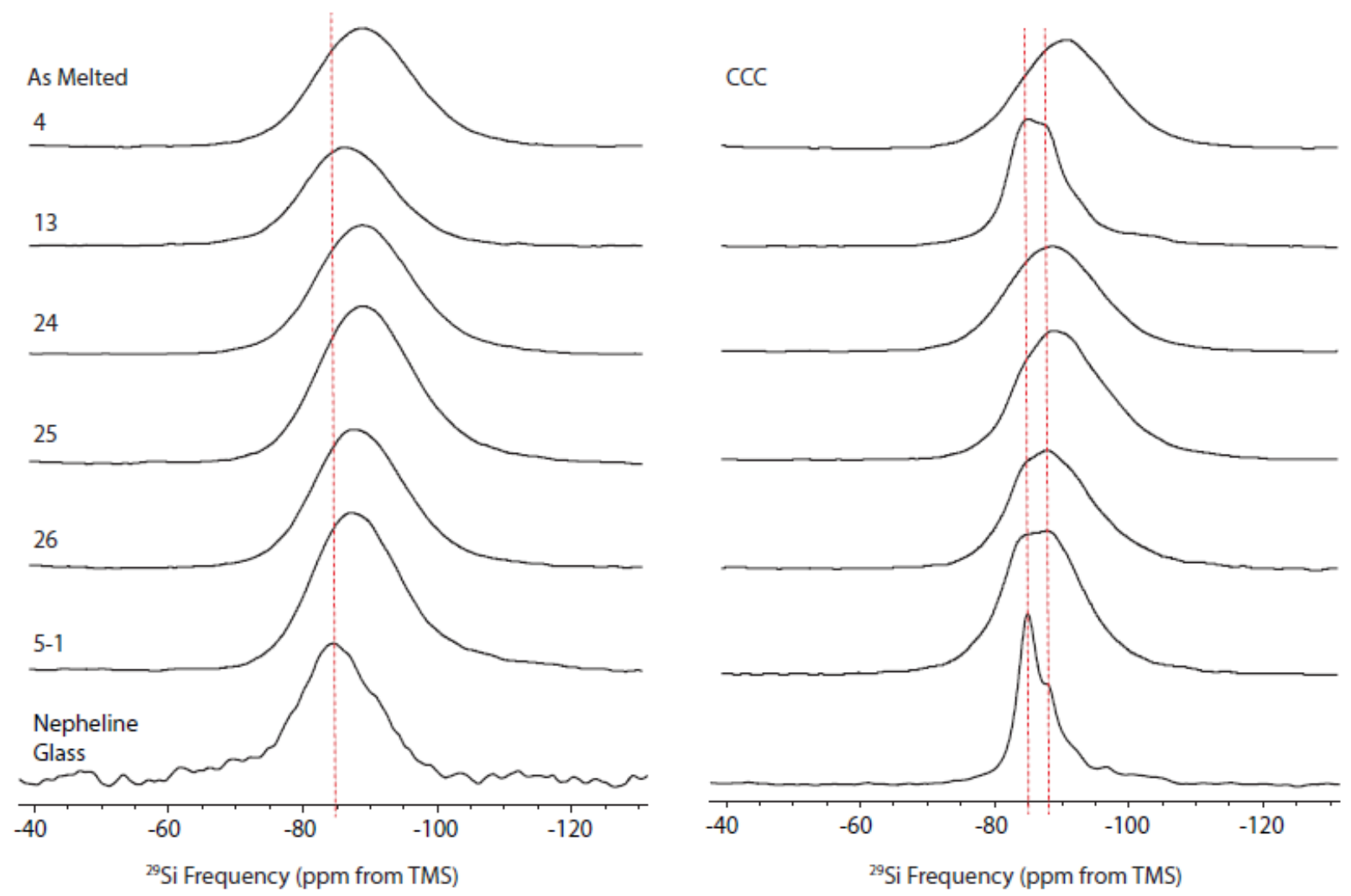

Figure 8: ${ }^{29}$ Si NMR of quenched (as melted) versus CCC glasses compared to nepheline glass and mineral standards. Lines for comparing across standards are -85 (both) and -88 ppm (CCC only). 


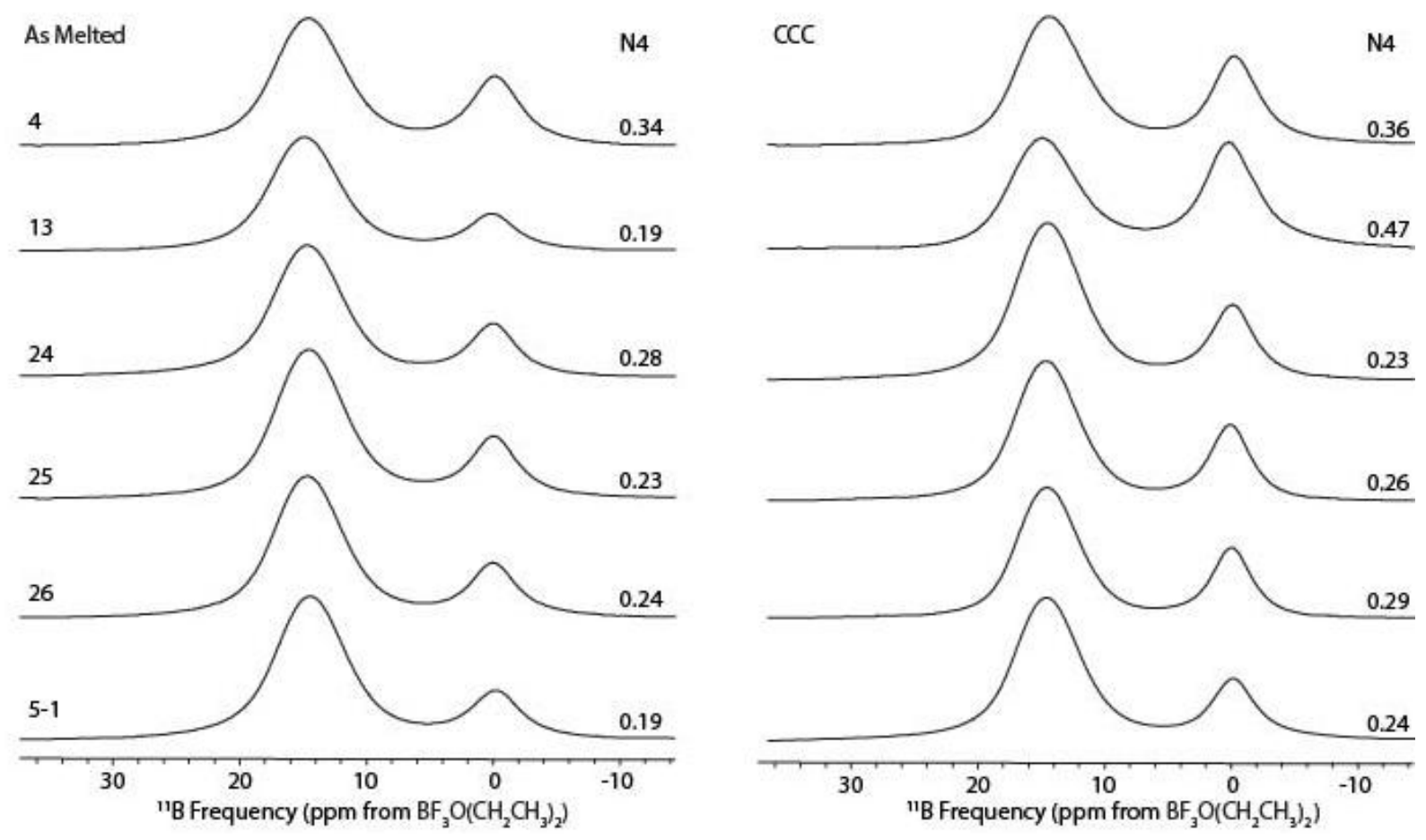

Figure 9: ${ }^{11}$ B NMR of quenched (as melted) versus CCC glasses. Values of N4 deduced from these spectra are shown in the righthand-side of each spectrum. 


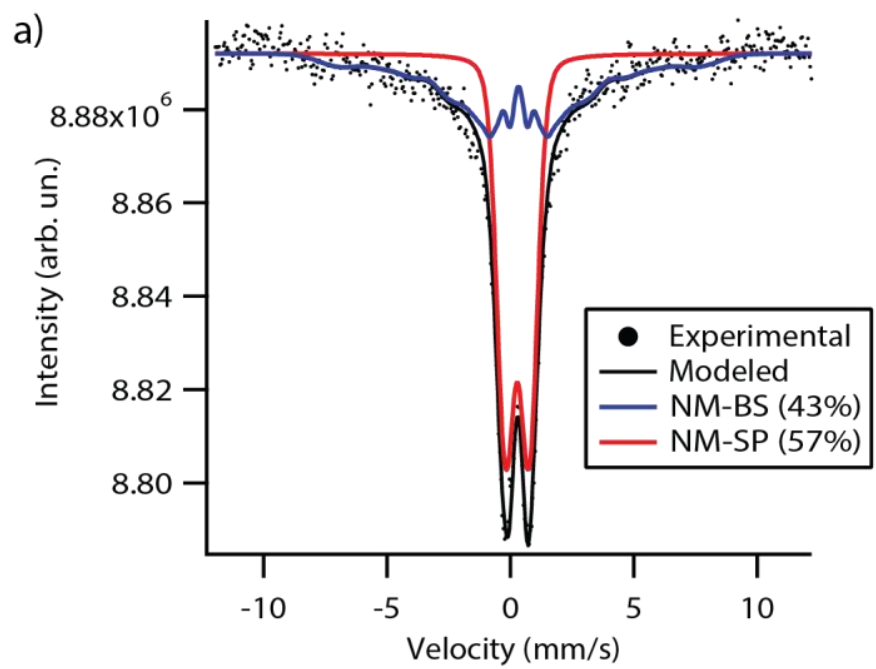

b)

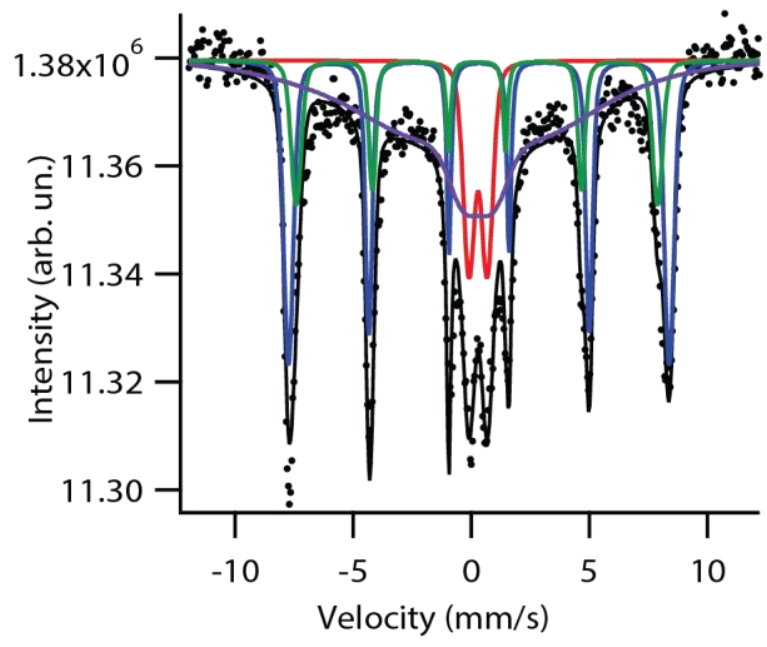

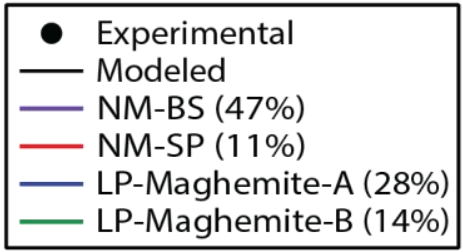

Figure 10: (color online) Fitted Mössbauer spectra of glass 26 (a) quenched and (b) CCC. Abbreviations: nanomaghemite (NM), broad sextet (BS), superparamagnetic (SP), large particle (LP). LP maghemite sextets $A$ and $B$ are mostly likely octahedral and tetrahedral sites, respectively. 